\title{
The Heidelberg Airborne Imaging DOAS Instrument (HAIDI) - a novel imaging DOAS device for 2-D and 3-D imaging of trace gases and aerosols
}

\author{
S. General ${ }^{1}$, D. Pöhler ${ }^{1}$, H. Sihler ${ }^{1}$, N. Bobrowski ${ }^{1}$, U. Frieß ${ }^{1}$, J. Zielcke ${ }^{1}$, M. Horbanski ${ }^{1}$, P. B. Shepson ${ }^{2}$, B. H. Stirm ${ }^{3}$, \\ W. R. Simpson ${ }^{4}$, K. Weber ${ }^{5}$, C. Fischer ${ }^{5}$, and U. Platt ${ }^{1}$ \\ ${ }^{1}$ Institute of Environmental Physics, University of Heidelberg, Heidelberg, Germany \\ ${ }^{2}$ Purdue University, Dept. of Chemistry, West Lafayette, IN, USA \\ ${ }^{3}$ Purdue University, Dept. of Aviation Technology, West Lafayette, IN, USA \\ ${ }^{4}$ Department of Chemistry and Biochemistry, University of Alaska, Fairbanks, AK, USA \\ ${ }^{5}$ University of Applied Sciences, Environmental Measurement Techniques, Düsseldorf, Germany
}

Correspondence to: S. General (stephan.general@iup.uni-heidelberg.de)

Received: 17 January 2014 - Published in Atmos. Meas. Tech. Discuss.: 7 March 2014

Revised: 18 July 2014 - Accepted: 28 August 2014 - Published: 9 October 2014

\begin{abstract}
Many relevant processes in tropospheric chemistry take place on rather small scales (e.g., tens to hundreds of meters) but often influence areas of several square kilometer. Thus, measurements of the involved trace gases with high spatial resolution are of great scientific interest. In order to identify individual sources and sinks and ultimately to improve chemical transport models, we developed a new airborne instrument, which is based on the well established Differential Optical Absorption Spectroscopy (DOAS) method. The Heidelberg Airborne Imaging DOAS Instrument (HAIDI) is a passive imaging DOAS spectrometer, which is capable of recording horizontal and vertical trace gas distributions with a resolution of better than $100 \mathrm{~m}$. Observable species include $\mathrm{NO}_{2}, \mathrm{HCHO}, \mathrm{C}_{2} \mathrm{H}_{2} \mathrm{O}_{2}, \mathrm{H}_{2} \mathrm{O}, \mathrm{O}_{3}$, $\mathrm{O}_{4}, \mathrm{SO}_{2}, \mathrm{IO}, \mathrm{OClO}$ and $\mathrm{BrO}$.

Here we give a technical description of the instrument including its custom-built spectrographs and CCD detectors. Also first results from measurements with the new instrument are presented. These comprise spatial resolved $\mathrm{SO}_{2}$ and $\mathrm{BrO}$ in volcanic plumes, mapped at Mt. Etna (Sicily, Italy), $\mathrm{NO}_{2}$ emissions in the metropolitan area of Indianapolis (Indiana, USA) as well as $\mathrm{BrO}$ and $\mathrm{NO}_{2}$ distributions measured during arctic springtime in context of the BRomine, Ozone, and Mercury EXperiment (BROMEX) campaign, which was performed 2012 in Barrow (Alaska, USA).
\end{abstract}

\section{Introduction}

To date, there are a series of remote sensing techniques which allow the retrieval of two dimensional trace gas distributions in the atmosphere on various scales. Satellite observations (e.g., GOME, GOME-2, OMI, SCIAMACHY) provide twodimensional distribution patterns on a global scale; however, the resolution is still rather coarse (several tens of $\mathrm{km}$ ). On smaller scales (several $\mathrm{km}$ ), tomographic inversion methods have been applied (Laepple et al., 2004; Pöhler, 2010). The resolution of this method depends on the number of light paths, therefore a high spatial resolution can only be achieved by installing a large number of instruments (Hartl et al., 2006). Another possibility are airborne measurements.

During recent decades a variety of airborne Differential Optical Absorption Spectroscopy (DOAS) measurements were reported (e.g., Wahner et al., 1990; Pfeilsticker and Platt, 1994; McElroy et al., 1999; Petritoli et al., 2002; Melamed et al., 2003; Bruns et al., 2004; Heue et al., 2005; Wang et al., 2005; Bruns et al., 2006; Wang et al., 2006; Heue et al., 2008; Dix et al., 2009; Merlaud et al., 2011; PradosRoman et al., 2011; Merlaud et al., 2012; Baidar et al., 2013), taking place at different flight altitudes and regions of the globe. The aim of these measurements ranged from studies of stratospheric chemistry to tropospheric point source emissions, but only a few of them used Imaging-DOAS (I-DOAS) techniques to acquire 2-dimensional spatially resolved trace 
gas distributions (e.g., Heue et al., 2008; Kowalewski and Janz, 2009; Popp et al., 2012). I-DOAS techniques are well established in remote sensing and were successfully used in many applications in the past. For instance, $\mathrm{BrO}$ formation in volcanic plumes has been studied using ground-based IDOAS measurements (e.g., Louban, 2005; Bobrowski et al., 2007). On a larger scale, satellite data have been used to quantify the strength of ship emissions based on SCIAMACHY $\mathrm{NO}_{2}$ distribution patterns in the Indian Ocean (Beirle et al., 2004) or emission from cities (Beirle et al., 2011).

Here we present the new Heidelberg Airborne Imaging DOAS Instrument (HAIDI), which can directly observe trace gas distributions at a spatial resolution of better than $100 \mathrm{~m}$ with high accuracy. Vertical profiles of trace gases can also be derived, allowing a three-dimensional reconstruction of the trace gas distribution. Moreover, a series of species can be observed simultaneously, e.g., $\mathrm{NO}_{2}, \mathrm{SO}_{2}, \mathrm{BrO}, \mathrm{IO}, \mathrm{HCHO}$, $\mathrm{C}_{2} \mathrm{H}_{2} \mathrm{O}_{2}, \mathrm{H}_{2} \mathrm{O}, \mathrm{O}_{3}$ and $\mathrm{O}_{4}$. Based on the observed patterns of trace gas distributions, sources and sinks of these species can be quantified and chemical processes including conversion rates and atmospheric lifetimes may be analyzed. Due to the high spatial resolution of our HAIDI instrument, individual sources located close to each other may be resolved and quantified separately. The results can be used for the validation of chemical transport models. Moreover, the variability of trace gas concentrations within a satellite pixel is one of the major issues that can be addressed with the new imaging DOAS instrument.

The general principle of operation of HAIDI is presented in Sects. 2-2.2 of this article, followed by a detailed description of the system's main components, like entrance optics, spectrographs, and charge-coupled device (CCD) cameras (Sects. 2.3-2.7). Sections 3 and 4 give an overview of the DOAS retrieval procedure and the software used for data acquisition. Furthermore, different configurations of the system are shown (Sect. 5), which were deployed to operate the system on a range of aircraft types. Up to now, HAIDI was used on smaller aircraft (ultralight and twin-engine propeller plane) for a total of 18 measurement flights. Some exemplary results from these flights are presented in Sect. 6, including the distribution of $\mathrm{SO}_{2}$ and $\mathrm{BrO}$ in the emission plume of $\mathrm{Mt}$. Etna (Sicily, Italy), the $\mathrm{NO}_{2}$ distribution over the metropolitan area of Indianapolis (Indiana, USA) as well as $\mathrm{BrO}$ and $\mathrm{NO}_{2}$ in the polar boundary layer around Barrow (Alaska, USA), measured in the context of the BRomine, Ozone, and Mercury EXperiment (BROMEX) campaign (see Table 1). For future measurements it is planned to use HAIDI on the German research aircraft HALO (modified businesses jet), which flies at an altitude of up to $15 \mathrm{~km}$. The instrumental setup for HALO is also presented here.

\section{The Heidelberg Airborne Imaging DOAS Instrument (HAIDI)}

The HAIDI system was built with the intention to retrieve hyperspectral images (images with two or three spatial dimensions, where each pixel contains spectral information) of large areas with high spatial resolution and in the shortest possible time, to capture also high dynamic processes. Therefore, the requirements to an instrument carrier are best fulfilled by an aircraft, which is not bound to roads and not restricted by physical features of the ground, like woods, rivers or hills. It can cover large distances in relatively short time and its high flight altitude allows to overview greater areas at once. At the same time, the flight altitude is still low enough to achieve a high spatial resolution compared to satellite measurements. By using the DOAS method (Platt and Stutz, 2008), the spectral information within each pixel of the hyperspectral images can be translated into the column density of one or several trace gases. This data can subsequently be assembled into maps to reveal the spatial distribution of the trace gases along various dimensions in space, depending on the choice of the instrument's viewing geometry.

\subsection{Remote sensing techniques for hyperspectral imaging}

Various methods exist to obtain hyperspectral images from remote sensing observations on satellites or aircraft. Two commonly used are the "whiskbroom" and the "pushbroom" scanning technique (Schowengerdt, 2006). Both are spectroscopic techniques and therefore rely on the detection of light dispersed by a prism or grating in order to obtain the spectral information of the images. However, the usage of the detector and the way images are acquired is very different. A hyperspectral image is in principle a 3-dimensional data set with two spatial dimensions and a third spectral one. The acquired data can thus be illustrated by a so-called hyperspectral cube. Figure 1 illustrates the measurement principle of the two techniques by means of the hyperspectral cube. The displayed cube is spanned by two spatial axes $(x, y)$ and a third spectral one $(\lambda)$. To acquire a hyperspectral image the full cube has to be scanned, i.e., information about each element of this 3-dimensional space has to be collected. The whiskbroom scanner uses its whole detector to record spectral information only (no information along $x$ or $y$ axis), therefore every pixel of the hyperspectral image has to be taken separately. The two missing spatial dimensions are acquired via scanning. In this case, the scanning in one dimension is achieved by the motion of the instrument carrier (aircraft, satellite, etc.) and the other dimension by a scanning prism or mirror that changes the instrument's viewing direction perpendicular to the flight track (e.g., nadir scanner in Fig. 2). The pushbroom technique instead requires a 2-dimensional detector (e.g., CCD-array), because here the detector records spectral information along with one spatial 
Table 1. List of conducted measurement campaigns to date, with corresponding time period and number of flights.

\begin{tabular}{lllll}
\hline Campaign & Base airport & Date of first flight & Date of last flight & Total number of flights \\
\hline I & Calatabiano, Sicily (Italy) & $07 / 07 / 2011$ & $09 / 07 / 2011$ & 4 \\
II & West Lafayette, Indiana (USA) & $23 / 10 / 2011$ & $25 / 10 / 2011$ & 3 \\
III & Barrow, Alaska (USA) & $13 / 03 / 2012$ & $31 / 03 / 2012$ & 11 \\
\hline
\end{tabular}

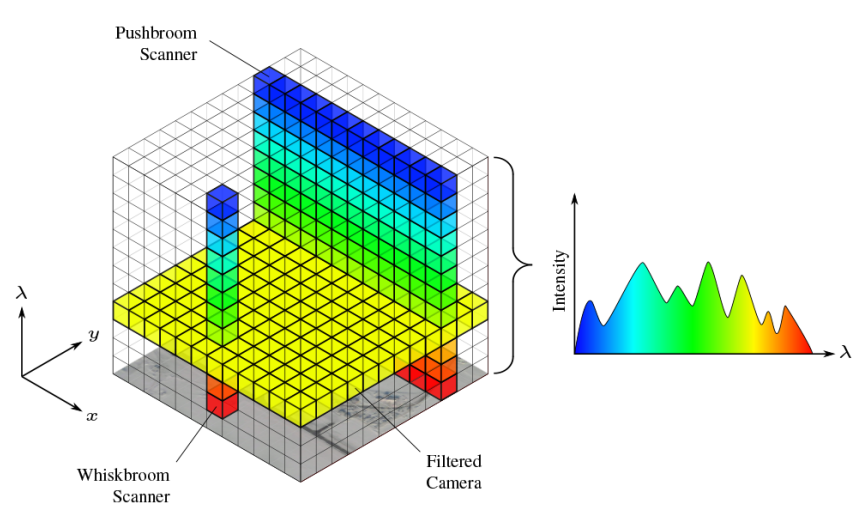

Figure 1. The hyperspectral cube is an often used schematic to visualize the different recoding techniques in hyperspectral imaging. Two dimensions of the cube represent the spatial dimensions of the image $(x, y)$, while the third axis represents the spectral dimension (i.e., the wavelength $\lambda$ ). For spectral images the whole cube has to be scanned. As can be seen, the whiskbroom technique can only acquire one pixel at a time with spectral information. So, scanning in two spatial dimensions is necessary to take spectral images. The pushbroom technique records a whole swath with spectral information at once and only needs to scan in one spatial dimension. A camera equipped with band-pass filters can take both spatial dimensions at once but will only contain spectral information from one narrow wavelength range.

dimension ( $x$ or $y$ ) simultaneously. The remaining spatial dimension is then also acquired through the motion of the instrument. This means that the pushbroom scanner can take a whole row of pixel, also called a swath, at once (e.g., forward telescope in Fig. 2).

\subsection{Measurement principle of HAIDI}

In practice, both scanning techniques (whiskbroom and pushbroom) described in Sect. 2.1 have their advantages and disadvantages (see Table 2). Therefore, it depends on the particular application and possible restrictions which of these techniques is suited best for the measurement of trace gas distributions. HAIDI is designed in such a way that it can be used with both techniques. This allows to reach a maximum of flexibility. In total, HAIDI can operate up to three fully independent passive DOAS instruments working with either the whiskbroom or the pushbroom technique. Each instrument features a telescope system to analyze scattered solar radiation between 300 and $407 \mathrm{~nm}$ (shiftable to $350-457 \mathrm{~nm}$ ) with a spectral resolution of about $0.5 \mathrm{~nm}$. To cover a preferably large area with one overflight, the HAIDI system always uses a whiskbroom scanner in nadir direction, as the scanning prism can cover a very wide field of view (FOV) across track without requiring a large or complex entrance optics. Moreover, the field of view can be easily changed by software according to the requirements of a particular mission (see Sect. 2.3). A drawback of the whiskbroom technique is that the spatial resolution varies with the scan angle of the system. This is caused by an increasing distance between entrance optics and ground towards the ends of a swath. Because of the resulting shape of the swath this is called the bow tie effect. The pushbroom technique does not suffer from this effect (other than caused by the curvature of the Earth) because here the varying distance is compensated by a likewise changing distance between the optical center of the lens and the individual fibers in the fiber column on the telescope side (see Fig. 5).

With the whiskbroom scanner applied in nadir direction, the horizontal distribution of trace gases can be determined. To get also the vertical profile of tropospheric absorbers, one of the following approaches can be used:

- Multiple downward scanners: The installation of HAIDI aboard the HALO research aircraft (see Sect. 5.3) is intended to use a set of three whiskbroom scanners pointed to different downward directions and thus to retrieve the vertical trace gas distribution by tomographic inversion methods applied to the different lines of sight (e.g., Heue, 2005). Because HALO flies at high altitude, much higher than the investigated air masses, this setup is most suitable to obtain vertical profile information. Whiskbroom scanners have furthermore the advantage of a constant spectral property for all viewing directions. Since the CCD detector is not operated in imaging mode, a whiskbroom scanner also does not need a mechanical shutter or equivalent techniques like frame transfer CCDs, which will reduce the sensitive area of the detector.

- Forward scanner: If vertical profile information is required for trace gases and aerosols at, or close to, the flight altitude with high vertical resolution, the setup with three nadir-looking whiskbroom scanners is not suited. Instead, one system is looking in forward direction, covering a range of elevation angles around $0^{\circ}$ (horizon direction). For this purpose, a pushbroom 
scanner is applied in limb geometry. In principle also a whiskbroom scanner can be used for the limb direction, but this has so far not been implemented because of space restrictions. A pushbroom scanner can be more compact due to the lack of motorized optics and in addition it is beneficial for the later profile retrieval that it measures all elevation angles at the same time (no need to compensate for different aircraft positions and orientations). However, since the detector of a pushbroom scanner records spectral and spatial information at the same time, it takes much longer (up to $300 \mathrm{~ms}$ ) to read out the CCD compared to a whiskbroom scanner. In this time, the detector is not sensitive to incident light (closed shutter), which reduces the achievable signal-tonoise ratio.

The general measurement principle and geometry of the HAIDI system is illustrated in Fig. 2. This setup uses both scanning techniques (one whiskbroom scanner in nadir direction and one pushbroom scanner in forward direction) and is especially used for smaller, low flying aircraft. An overview to the different instrumental setups of the HAIDI system can be found in Sect. 5. Independent of the used scanning technique, all setups are working on the same principle. Solar radiation with the intensity $I_{0}(\lambda)$ is passing Earth's atmosphere and is thereby partly absorbed by different trace gases and aerosols. This light is then reflected on the ground or scattered in the atmosphere by Rayleigh and Mie scattering before it is collected by HAIDI's telescopes with the remaining intensity $I(\lambda)$. As can be seen in Fig. 2, the instantaneous field of view (IFOV) of the telescopes differs for the two scanning techniques. Due to the reasons discussed above, the whiskbroom scanner has to record all pixel sequentially in order to obtain hyperspectral images. Because of the aircraft's motion during the scan this leads to a diagonal strip pattern of the observed area which is typical for the whiskbroom technique. Each strip is called a swath and currently consists of up to 128 scans, which are taken while the whiskbroom scanner moves the viewing direction of the telescope along one swath. The IFOV of the forward-looking telescope covers all viewing directions at the same time instead, but has only a narrow total FOV due to the restrictions of the pushbroom technique. In case of the nadir observations, the results from the following DOAS analysis (Sect. 3.1) can then be plotted into spatial maps by reconstructing the path taken by the light from the sun to the telescopes (Sect. 3.2).

Beside the entrance optics, HAIDI features a temperature stabilized spectrograph-detector unit (Sect. 2.5) for each whiskbroom or pushbroom scanner in order to disperse and detect the gathered light. These are stored in a special instrument rack inside the aircraft and are connected to the entrance optics by a fiber-optical system of several meter length. In the following sections the different components of the HAIDI system are described in detail, beginning with the entrance optics for the whiskbroom and pushbroom scanners.

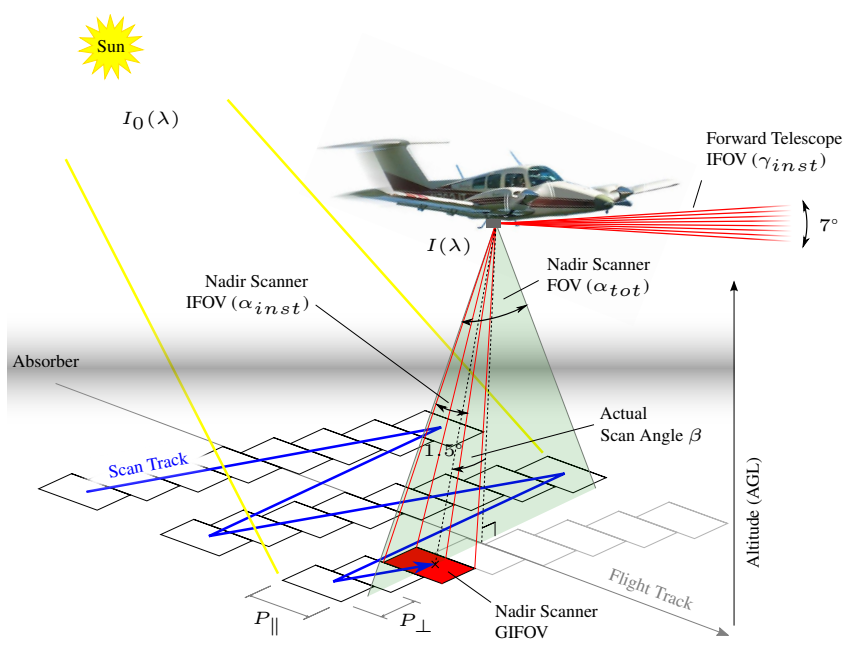

Figure 2. Schematic showing the measurement principle of the HAIDI system in the configuration for low flying aircraft (e.g., Flight Design CTLS, see Sect. 5.1), which uses a whiskbroom scanner in nadir direction and a pushbroom scanner in forward direction. The instantaneous field of view of the two telescopes $\left(\alpha_{\text {inst }}, \gamma_{\text {inst }}\right)$ is marked in red. While the whiskbroom scanner uses a sweeping prism to rotate the viewing direction of the nadir telescope by angle $\beta$ across track direction, resulting in the total FOV $\alpha_{\text {tot }}$ (green), the forward-looking telescope observes multiple viewing angles at once.

\subsection{The nadir scanner (whiskbroom)}

The entrance optics of the nadir scanner is usually pointed to the downward direction of the aircraft in order to scan the ground beneath. Light collected by its telescope is therefore mainly ground-scattered (see Sect. 3.2.1). The technical setup (Fig. 3) essentially consists of a servo actuated prism that sweeps the viewing direction of the instrument perpendicular to the flight direction and a telescope that couples the collected light into a fiber optics cable. The fiber optics cable then transfers the light to a temperature stabilized spectrograph inside the aircraft (see Sect. 2.5).

Viewed from the telescope side, the first part of the fiber optics cable consists of a mono fiber (single optical fiber) with a core diameter of $1250 \mu \mathrm{m}$. Attached to this mono fiber is a fiber bundle with a length of $5 \mathrm{~m}$ via standard F-SMA (SMA 905) fiber optic connector. The bundle consists of 31 individual fibers with a core diameter of $150 \mu \mathrm{m}$ which are arranged as a tightly packed circular bundle at the coupling and as a column at the spectrograph side, forming its entrance slit. The mono fiber is connected upstream to the bundle in order to mix the incident light from the telescope, so that all fibers at the spectrograph's entrance slit are illuminated homogeneously with the same spectral information during the measurements. This is necessary because the instrument's slit function is not constant over the height of the detector and a varying weighting of individual detector parts due to an inhomogeneous illumination of the slit would cause changes 
Table 2. Advantages and disadvantages of the different remote sensing techniques used by the HAIDI system.

\begin{tabular}{|c|c|}
\hline Advantages & Disadvantages \\
\hline \multicolumn{2}{|c|}{ Whiskbroom Scanner } \\
\hline $\begin{array}{l}\text { - can cover a very wide swath with- } \\
\text { out complex entrance optics } \\
\text { - swath can easily be changed by } \\
\text { software } \\
\text { - no mechanical shutter required } \\
\text { - system has the same spectral slit } \\
\text { function for all viewing directions }\end{array}$ & $\begin{array}{l}\text { - requires moving parts (scanner) } \\
\text { - pixel distortion (bow tie effect) } \\
\text { - requires more space for } \\
\text { installation (motorized optics) } \\
\text { - movement of instrument and op- } \\
\text { tics during integration time makes } \\
\text { viewing geometry more complex }\end{array}$ \\
\hline \multicolumn{2}{|c|}{ Pushbroom Scanner } \\
\hline $\begin{array}{l}\text { - all pixel of a swath are taken at the } \\
\text { same time and under same condi- } \\
\text { tions } \\
\text { - no pixel distortion } \\
\text { - narrow swath can be realized with } \\
\text { very simple and compact entrance } \\
\text { optics } \\
\text { - no moving parts (scanner) }\end{array}$ & $\begin{array}{l}\text { - typically requires mechanical } \\
\text { shutter } \\
\text { - readout time (closed shutter) is } \\
\text { lost for recording signal } \\
\text { - separate slit function for each } \\
\text { viewing direction } \\
\text { - change of swath only possible } \\
\text { with change of optics }\end{array}$ \\
\hline
\end{tabular}

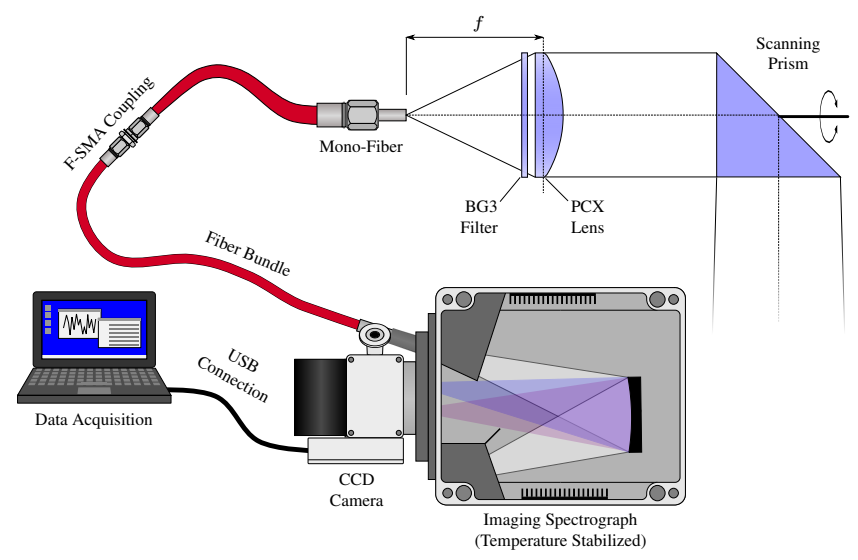

Figure 3. Setup of HAIDI's nadir scanner (whiskbroom scanner). A sweeping prism guides the light from different viewing directions to the telescope of the system. From there the light passes through a fiber optic cable to the spectrograph. Hardware control and data acquisition is done by a computer which is connected via USB.

in the overall instrumental slit function. This, in turn, would result in residual structures during the DOAS analysis, when comparing the Fraunhofer reference spectrum to a measurement spectrum (Sect. 3).
The nadir scanner uses a quartz prism instead of a mirror to redirect incident light into its telescope, because the reflectivity of metallic surfaces (mirror) depends not only on the angle of incident but also on the polarization direction (Williams, 1982). As the sunlight becomes partly polarized by scattering in the atmosphere (Liou, 2002), a mirror can act as a polarization filter and thus affect the sensitivity of the system to different components in the incident radiation. The total internal reflection of a prism instead is polarizationindependent. Only the reflectivity of the prism surfaces varies slightly with polarization direction due to Fresnel reflection. However, for almost normal incident light, like in case of the nadir scanner prism, the polarization dependence of the Fresnel reflection vanishes.

In order to reach a maximum light throughput and thus a high signal-to-noise ratio at short integration times (see Sect. 2.7.2) the numerical apertures (NA) of HAIDI's optical components are adapted to give the best matching $\left(\mathrm{NA}_{\text {lens }}=\right.$ $0.25, \mathrm{NA}_{\text {fiber }}=0.22, \mathrm{NA}_{\text {spectrograph }}=0.16$ ). The corresponding focal length of the telescope lens is $48.1 \mathrm{~mm}$ at $350 \mathrm{~nm}$, which yields an instantaneous field of view (IFOV) of $\alpha_{\text {inst }}=$ $1.5^{\circ}$ (see Fig. 2) with the core diameter of the mono fiber $(1250 \mu \mathrm{m})$. Thus, for an assumed flight altitude of $1500 \mathrm{~m}$, the ground projected instantaneous field of view (GIFOV) of the telescope is about $40 \mathrm{~m}$ in diameter. The total angle $\alpha_{\text {tot }}$ covered by the whiskbroom scanner during one swath is called its field of view (FOV) and is typically set to $50^{\circ}$. Therefore, the swath width equals approximately the flight altitude above ground level (a.g.l.). Because of the motion 

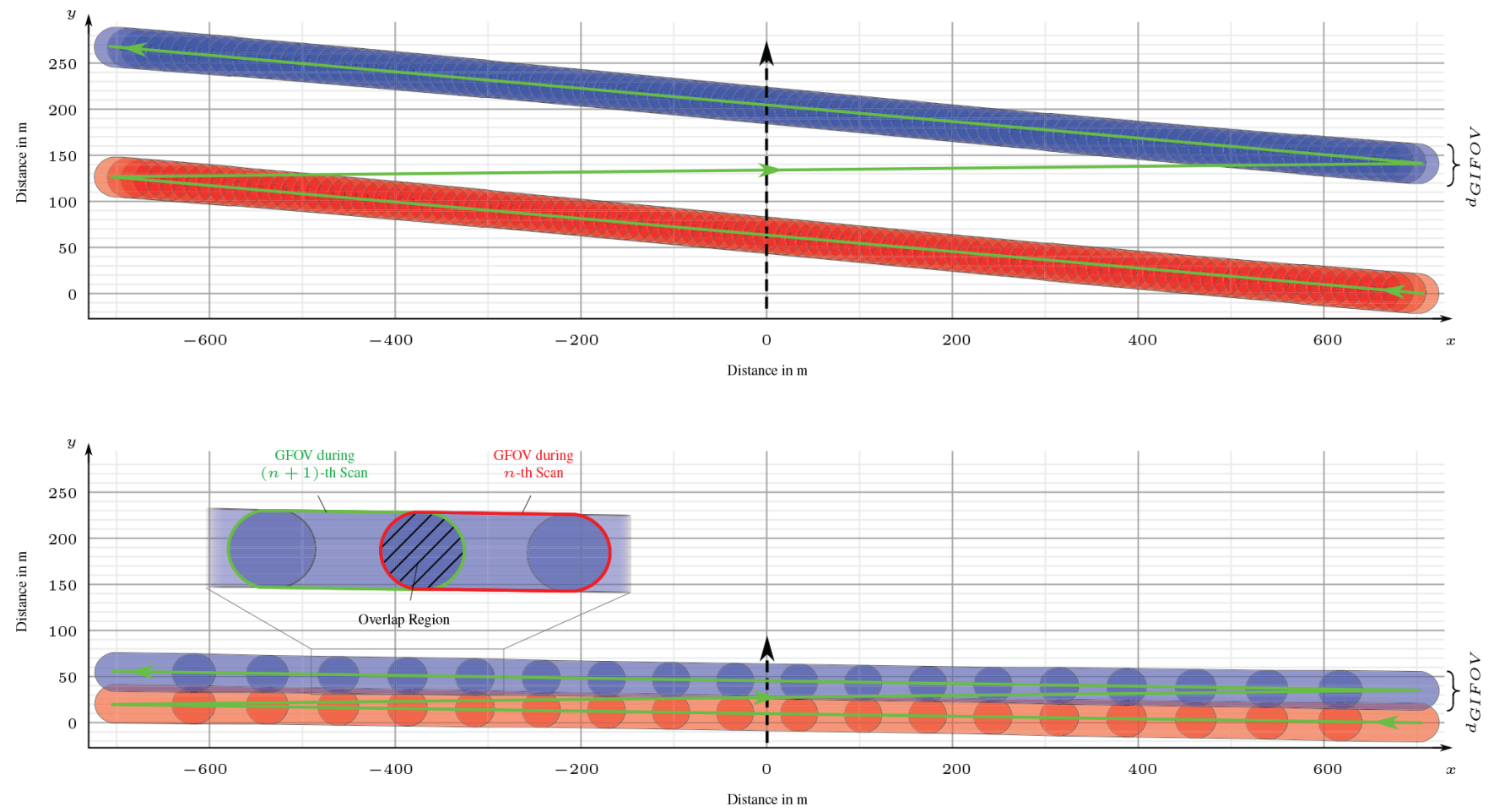

Figure 4. Calculation of the nadir scanner's GFOV for two sequent swaths. The direction of the scan is from right to left (along the green line) while the aircraft travels in the direction of the positive $y$ axis at $x=0$ (dashed line). Each swath is subdivided into several segments, which indicate the area covered by the scanner's GIFOV during the integration time of a single scan (i.e., the GFOV during a single scan). As there is no delay between scans, the GFOV of sequent scans overlaps (see enlarged view). The areal coverage can be adapted to the flight conditions by altering the total number of scans per swath $n_{\text {scan, total }}$. The GFOV in the lower subfigure is calculated for a total number of 32 scans per swath while the upper one uses the maximum of 128 scans per swath. All remaining parameters are the same for both figures: pitch $=0^{\circ}$, roll $=0^{\circ}, v_{\mathrm{g}}=55 \mathrm{~m} \mathrm{~s}^{-1}, h_{\text {a.g.l. }}=1500 \mathrm{~m}, t_{\text {back }}=250 \mathrm{~ms}, t_{\text {int }}=20 \mathrm{~ms}$.

of the aircraft and the prism during a scan, the actual spatial resolution achieved by the instrument depends on several factors, like integration time, aircraft speed, prism rotation speed and number of co-added scans. The size of one ground pixel (scanned area according to the number of coadded scans) is approximately given by the following equations:

$$
\begin{aligned}
P_{\|}= & \left(n_{\text {swath }}-1\right) \times t_{\text {int }} \times n_{\text {scan, total }} \times v_{\mathrm{g}} \\
& +\tan \left(\frac{\alpha_{\text {inst }}}{2}\right) \times h_{\text {a.g.l. }} \times 2 \\
P_{\perp}= & \left(\tan \left(\frac{\alpha_{\text {tot }}}{2}\right) \times \frac{n_{\text {scan }}}{n_{\text {scan, total }}-n_{\text {scan, back }}}\right. \\
& \left.+\tan \left(\frac{\alpha_{\text {inst }}}{2}\right)\right) \times h_{\text {a.g.l. }} \times 2,
\end{aligned}
$$

where $P_{\|}$is the pixel size in flight direction (Fig. 2), $P_{\perp}$ the pixel size perpendicular to the flight direction, $n_{\text {swath }}$ the number of co-added swaths, $n_{\text {scan }}$ the number of coadded scans within a swath, $n_{\text {scan, total }}$ the total amount of scans taken during one swath (typically 128), $t_{\text {int }}$ the integration time of a single scan, $n_{\text {scan, back }}$ the quantity of scans taken during the back scan $\left(n_{\text {scan, back }}=\frac{t_{\text {back }}}{t_{\text {int }}}, t_{\text {back }} \approx\right.$
$250 \mathrm{~ms}), h_{\text {a.g.l. }}$ the altitude of the aircraft above ground level and $v_{\mathrm{g}}$ the ground speed of the aircraft.

To calculate the actual shape of the nadir scanner's ground projected field of view (GFOV), including perspective distortion due to off-nadir viewing directions, requires a much more complex algorithm. Figure 4 illustrates such a calculated GFOV for typical flight conditions on smaller aircraft. The plots contain two consecutive swaths each; the first of which is marked in red, and the second of which is marked in blue to show the areal coverage of the scanner. To get the best areal coverage, the gap between consecutive swaths should be as small as possible. The distance between two swaths depends on a number of parameters, e.g., flight altitude above ground level, aircraft speed, integration time and number of scans per swath. However, in general the distance covered by the aircraft during the time for one swath should be equal to the extent of the GIFOV in flight direction, $d_{\mathrm{GIFOV}}$, in order to minimize the gap and avoid overlap:

$v_{\mathrm{g}} \times t_{\text {int }} \times n_{\text {scan, total }} \stackrel{!}{\approx} d_{\text {GIFOV }}$.

Because the aircraft speed usually cannot be influenced and the integration time per scan depends on the intensity of 


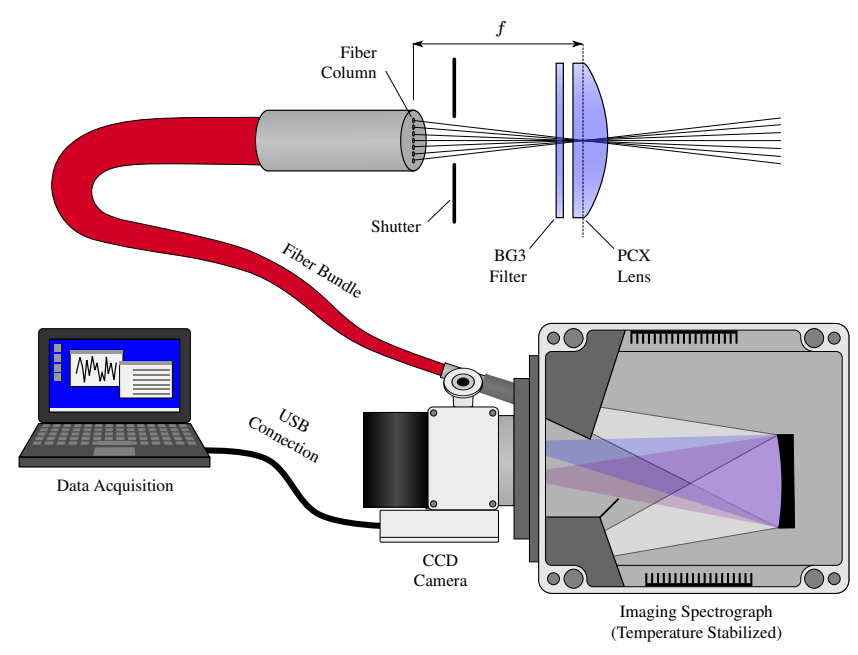

Figure 5. Setup of HAIDI's forward-looking telescope (pushbroom scanner). The individual fibers of the fiber optics bundle, which connects the telescope with the imaging spectrograph, are arranged to a slit on both sides. This leads to 31 simultaneous viewing directions/elevation angles. A mechanical shutter protects the detector from incident light during the readout process. Hardware control and data acquisition is done by a computer which is connected via USB.

incident light, the distance between two swaths is typically adjusted by choosing a different number of scans per swath (1 to 128). For an accurate reconstruction of the GFOV also pitch and roll angles of the aircraft have to be taken into account, which can be handled by the used algorithm as well.

For later plotting of the measured data into spatial maps, it is important to know the exact deflection angle $\beta$ (see Fig. 2) of the nadir scanner's prism for each single scan of a swath. For this reason, the pulse-width modulation (PWM) signal that controls the motion of the servo motor (HS-7940TH from HiTEC) is synchronized with the recording of the scans (Sect. 2.7). Together with information from the aircraft's GPS (latitude, longitude, altitude) and inertial measurement unit (pitch, roll and heading angles), the measured data can then be plotted in a map at the position of the particular GFOV with high spatial accuracy. A detailed description of the servo motor control and the georeferencing procedure can be found in General (2014).

\subsection{The forward-looking telescope (pushbroom)}

The entrance optics of the forward-looking instrument collects scattered sunlight from directions close to the horizon (Fig. 2). This viewing geometry yields very long absorption paths, especially close to the flight altitude (see Sect. 3.2.3). For this reason, the forward-looking telescope is well-suited for the profile retrieval of trace gases in the lower troposphere on smaller, low flying aircraft.
Due to technical reasons in the presented aircraft, the forward-looking telescope could only be realized with the pushbroom technique. However, the potential to realize a wider swath with a whiskbroom scanner would not give any significant advantage for the forward-looking telescope to derive trace gas profiles. With the pushbroom technique, spectral information is recorded along the rows of the CCD array, while the column-direction of the detector is used to image the different elevation angles of the instrument simultaneously. Thus, unlike the whiskbroom technique, the pushbroom technique requires a fiber optical cable that preserves spatial information and a spectrograph-detector unit with imaging capabilities. Therefore, the fibers of the fiber optics bundle are arranged into columns at both ends with corresponding fiber ends having the same position in the column. In total, the fiber optics bundle has a length of $5 \mathrm{~m}$ and consists of 31 individual fibers with a core diameter of $150 \mu \mathrm{m}$ each (diameter with cladding: $190 \mu \mathrm{m}$ ). Also in this case, the exit end of the fiber bundle directly acts as the entrance slit of the imaging spectrograph. The other end is placed in the focal point of the telescope. Due to the different distances of the fibers to the optical axis of the telescope, this results in 31 different viewing directions/elevation angles. As the height of the fiber columns is about $5.9 \mathrm{~mm}(31 \times 190 \mu \mathrm{m})$, the telescope (lens: $d=25 \mathrm{~mm}, f=48.1 \mathrm{~mm}$ ) yields a total vertical viewing angle of about $7^{\circ}$. The horizontal viewing angle of the telescope is $\sim 0.2^{\circ}$ and corresponds to the vertical viewing angle of a single fiber. The exact orientation of the instrument depends on the scientific question. If plumes are investigated close to the flight altitude (campaign I in Table 1), it is adjusted approximately to the horizon for the expected average pitch angle during flight. For the campaigns II and III more sensitivity at low altitudes was required, thus the range was set to elevation angles between $-5^{\circ}$ and $+2^{\circ}$.

\subsection{Instrument rack}

HAIDI's imaging spectrographs and CCD cameras are housed in the so-called instrument rack (Fig. 6), which is a modified 19-inch aluminum rack with a height of 6 rack units $(19 \times 20 \times 10.5 \mathrm{inch})$. In the current state, the instrument rack can store up to three spectrograph-detector units that are of identical design to be applicable for the whiskbroom scanner setup and the pushbroom setup as well. In addition to spectrograph mountings, which withstand load factors of at least 9 times the acceleration due to gravity, the instrument rack also features a temperature-stabilized section for the spectrographs and DC-to-DC converters to power the nadir scanner servo motors. The temperature stabilization is realized by an Air-to-Air Peltier (PE-127-14-11-S from Supercool) system controlled by a custom-built electronics for heating and cooling. This system uses four temperature sensors (ADT7410 from Analog Devices) to monitor the internal air and spectrograph temperature. In order to minimize the heat transfer into the temperature stabilized vol- 


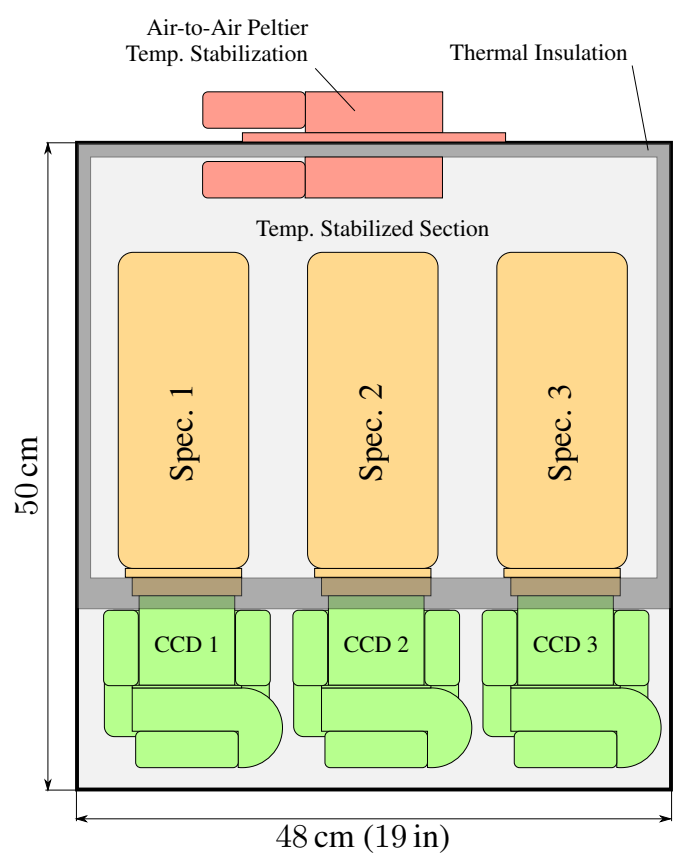

Figure 6. Schematic of the HAIDI instrument rack with three spectrographs and detectors installed. The Air-to-Air Peltier temperature stabilization controls the temperature inside the gray shaded volume. Since the detectors have a separate cooling for the CCD, which produces considerable amounts of heat, they are located outside the temperature stabilized section.

ume, the internal air temperature is normally set to a value close to ambient temperature. Furthermore, the temperature stabilized compartment of the housing (see Fig. 6) is lined with a $10 \mathrm{~mm}$ layer of PE-foam (MP15FR from Wulfmeyer) for thermal insulation and includes only the spectrographs and no heat producing electronics. Thus, the temperature stabilization can usually work on low power consumption $(<10 \mathrm{~W})$. Due to the high thermal capacity of the aluminum spectrographs $\left(\sim 2.7 \mathrm{~kJ} \mathrm{~K}^{-1}\right.$ per spectrograph), it takes some time to equilibrate the spectrograph temperature to the air temperature inside the rack (about $1 \mathrm{~h}$ for a temperature difference of $5 \mathrm{~K}$ ), but this makes the temperature stabilization also relatively immune to short interruptions in the power supply.

\subsection{Imaging spectrographs}

The imaging spectrographs used by HAIDI were developed especially for the purpose of an airborne imaging DOAS instrument, because no commercially available spectrograph fulfilled the requirements regarding size, light throughput, spectral resolution and imaging capabilities at the same time. HAIDI's spectrographs are based on a die-cast aluminum box (BOPLA A140 SI) which was complemented with a detector

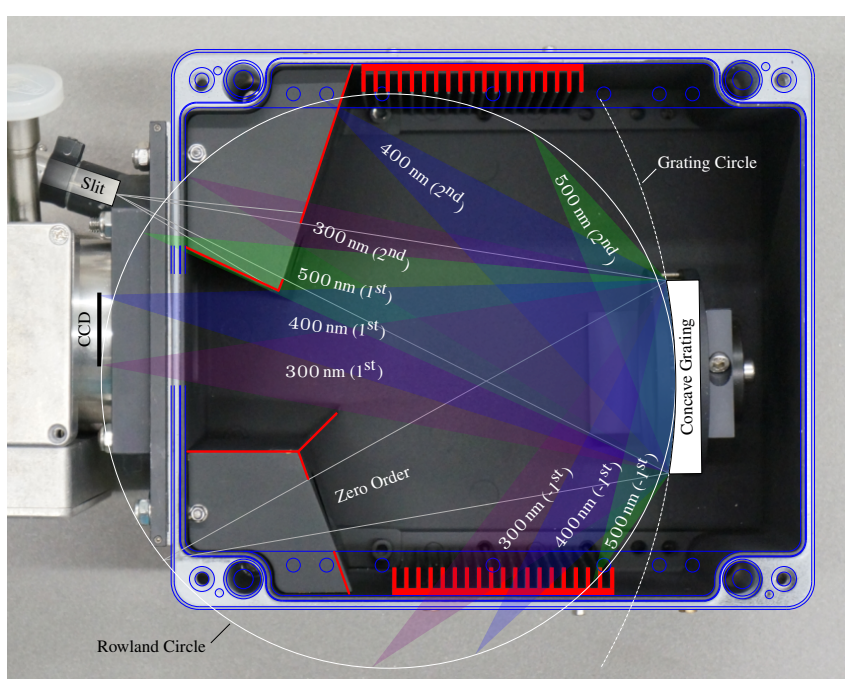

Figure 7. Opened HAIDI imaging spectrograph showing the diffraction angles of the grating for different wavelengths $(300 \mathrm{~nm}$ (violet), $400 \mathrm{~nm}$ (blue), $500 \mathrm{~nm}$ (green)) and orders. Due to the concave grating the spectrograph works on the basis of the Rowland circle. For an optimized imaging on flat surfaces (e.g., CCD) the shape of the Rowland circle is slightly altered by a special groove pattern of the grating (flat-field correction). This is why the entrance slit is not located exactly on the illustrated circle. Installed light traps are marked in red.

flange, a mount for the diffraction grating and some light traps.

The imaging spectrographs use a diffraction grating of type $52300080\left(1200\right.$ lines $\left.\mathrm{mm}^{-1}\right)$ from Jobin Yvon. This is a concave holographic grating with a focal length of $21 \mathrm{~cm}$ and a f-number of 3.2, which matches the f-numbers of the telescopes and the optical fibers quite well (Sect. 2.3). Due to the focusing properties of concave gratings, additional optical elements are not required by the system. This design has several advantages. On the one hand it makes the spectrographs very easy to adjust in comparison to Czerny-Turner setups which have many more degrees of freedom for adjustment (Neumann, 2013). On the other hand light loss due to additional optical surfaces is avoided. Another important advantage for airborne applications is that fewer optical compounds make the system less sensitive to vibrations.

Apart from mechanical benefits, concave holographic gratings offer some imaging properties which cannot be achieved with ruled gratings. For instance, aberration effects like astigmatism are significantly reduced by a special groove pattern of the used holographic grating. This also improves the imaging on flat surfaces (flat-field correction), resulting in an almost homogeneous imaging quality over the whole surface of the chip (see Fig. 8b). As further advantages, concave holographic gratings produce less stray light than ruled gratings (Palmer and Loewen, 2005), and the zero order of the diffracted light can easily be guided to a light trap with small aperture, because it is also focused. Stray light in the 
Table 3. Characteristics of HAIDI's imaging spectrographs.

\begin{tabular}{|c|c|}
\hline \multicolumn{2}{|c|}{ Spectrograph characteristics } \\
\hline Dimensions & $24 \times 20.5 \times 9.5 \mathrm{~cm}$ \\
\hline Weight & $3.0 \mathrm{~kg}$ \\
\hline Grating type & flat field concave holographic \\
\hline Configuration & quasi-Littrow \\
\hline Grating diameter & $70 \mathrm{~mm}$ \\
\hline Groove density & 1200 lines $\mathrm{mm}^{-1}$ \\
\hline Spectral range & 300 to $407 \mathrm{~nm}(350$ to $457 \mathrm{~nm})$ \\
\hline Dispersion & $4 \mathrm{~nm} \mathrm{~mm}^{-1}$ \\
\hline Focal length & $21 \mathrm{~cm}$ \\
\hline f-number & 3.2 \\
\hline typ. resolution & $\sim 0.5 \mathrm{~nm}$ \\
\hline
\end{tabular}

spectrograph is further reduced to less than $0.5 \%$ (for a spectral range of 300 to $407 \mathrm{~nm}$, measured with a halogen lamp) of the original light intensity by covering the inside with Krylon ultraflat black painting which has a very low reflectivity in the infrared wavelength region (Wan et al., 1999) and additional light traps for higher order diffracted light (see Fig. 7).

Usually the wavelength range of the spectrographs is set to $300-407 \mathrm{~nm}$. However, the spectrographs also allow to rotate the grating to shift the observable wavelength range to 350 $457 \mathrm{~nm}$. The spectral resolution (full width at half maximum (FWHM) of emission lines) achieved by the system is about $0.5 \mathrm{~nm}(\approx 5$ pixel $)$, as can be seen in Fig. 8 . A list with the characteristics of the spectrographs can be found in Table 3 .

\subsection{CCD cameras}

Also HAIDI's CCD cameras are custom-made in cooperation with khs-instruments (Munich, Germany) in order to optimize their size and weight. This makes it possible to install the whole system also on very small aircraft, e.g., ultralight planes. The detectors feature CCD30-11 chips from e2v (Chelmsford, England), which have $1024 \times 256$ pixel (pixel size: $26 \times 26 \mu \mathrm{m}$ ) and are back illuminated for enhanced sensitivity in the UV wavelength region (quantum efficiency of 50 to $65 \%$ between 300 and $400 \mathrm{~nm}$ ). Additional specifications of the detectors can be found in Table 4. Apart from the compact design, the advantage of such a custom made detector is that its readout electronics can also generate the PWM signal which controls the motion of the nadir scanner's servo motor. This ensures that the recording of scans is synchronized with the scan angle $\beta$ of the instrument (see Sect. 2.3), which is therefore known precisely for each scan of a swath. Also the signal for the mechanical shutter is generated by the electronics, when the detector is operated in 2-D (full frame readout) mode.

In order to reduce the dark current signal of the detector at higher integration times and warmer environments, the detector is equipped with a thermoelectric cooling (Peltier element) and its housing is filled with Argon to reduce thermal
Table 4. Characteristics of HAIDI's custom-built CCD cameras.

\begin{tabular}{ll}
\hline & CCD camera characteristics \\
\hline Dimensions & $13.0 \times 13.0 \times 12.0 \mathrm{~cm}$ \\
Weight & $1.5 \mathrm{~kg}$ \\
CCD & $\mathrm{e} 2 \mathrm{v} \mathrm{CCD} 30-11$ (back-illuminated) \\
Resolution & $1024 \times 256$ pixel \\
Image area & $26.6 \times 6.7 \mathrm{~mm}$ \\
Cooling & max. $40 \mathrm{~K}$ below ambient temp. \\
Min. int. time & $10 \mathrm{~ms}$ (full vertical binning) \\
& $297 \mathrm{~ms}$ (full frame readout) \\
typ. Readout Frequ. & $1 \mathrm{MHz}$ \\
\hline
\end{tabular}

conductivity and avoid water condensation. The Peltier element is able to cool the chip down to $40 \mathrm{~K}$ below ambient temperature. Normally, the detector is operated at a temperature of $0{ }^{\circ} \mathrm{C}$, where the typical dark current signal is in the order of $80 \mathrm{e}^{-}$pixel $^{-1} \mathrm{~s}^{-1} \approx 5$ counts pixel ${ }^{-1} \mathrm{~s}^{-1}$. This is sufficiently low for measurements with high sensitivity.

\subsubsection{Linear range of the CCD}

An important characteristic of a CCD detector is its linearity in response to incident light. Ideally, the signal gained from a pixel (counts $\mathrm{ms}^{-1}$ ) should be linear with respect to the amount of incident photons over the full intensity range, but normally this is not the case. Instead, most detectors show a decreasing sensitivity to incident photons when approaching the full well capacity of the individual pixels (Fellers and Davidson, 2014). Since nonlinearities in the intensity of recorded spectra can lead to residual structures in the DOAS analysis (Sect. 3), it is mandatory to know the linear range of the used detector.

To test the linearity of HAIDI's CCD detectors, a large number of spectra from a temperature stabilized LED (Cree XP-E Royal Blue) were taken with slowly increasing exposure time. In this way the intensity range of the CCD could be sampled with high accuracy. Afterwards, the measured signal (in counts $\mathrm{ms}^{-1}$ ) was normalized to the value at 30000 counts for each pixel and then plotted versus the corresponding intensity level (detector counts). Figure $9 \mathrm{a}$ and $\mathrm{b}$ show the result of the test for the different readout modes of the detector. As can be seen, the response of the detector to incident photons is almost linear in the range between 0 and 40000 counts (analog-to-digital converter resolution: 16 bit $\Rightarrow$ max. 65536 counts). For higher intensity levels, the sensitivity to incident photons decreases quickly and should therefore be avoided. Recorded spectra in the range between 0 and 40000 counts can be corrected subsequently since the nonlinearity in this region can be well described by a second-order polynomial. After linearization with this polynomial, the remaining nonlinearity in the measured counts per millisecond is less than $5 \times 10^{-3}$ (see Fig. $9 \mathrm{c}$ to f). 

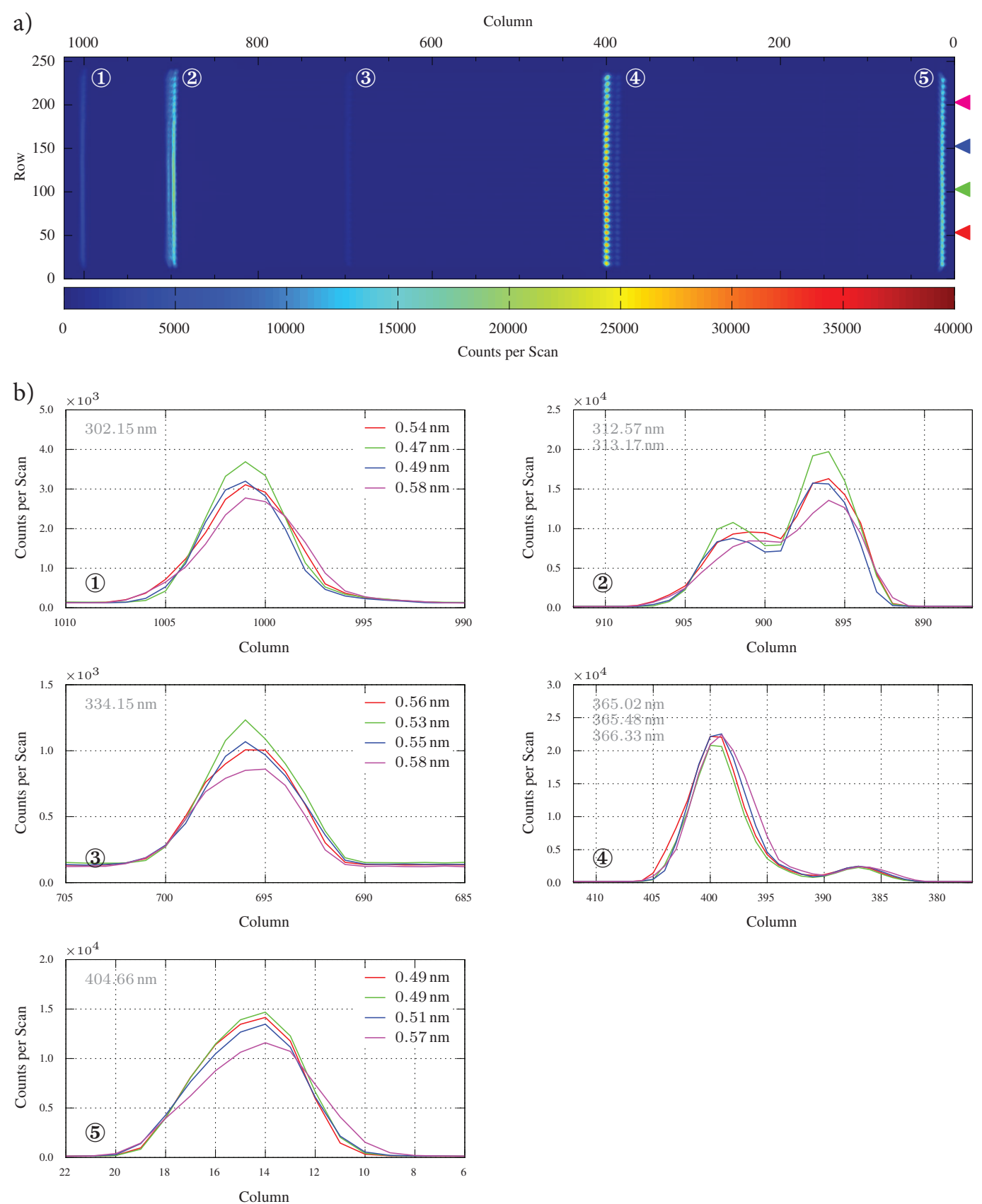

Figure 8. Mercury emission lines between 300 and $407 \mathrm{~nm}$ (marked with (1)-(5) in both figures) taken by HAIDI's detector in full frame readout mode. (a) Intensity plot showing the image of the entrance slit for different emission lines. (b) Mercury lines plotted for different rows of the CCD (see markers in a). The full width at half maximum (FWHM) of the individual lines is given in the upper right corner of the plots. As can be seen, the peak width increases slightly towards the edges of the CCD, resulting in a lower spectral resolution. This is due to Petzval field curvature (Kidger, 2002). However, the double emission line $312.57 \mathrm{~nm} / 313.17 \mathrm{~nm}$ can still be resolved for all CCD rows.

\subsubsection{Signal-to-noise ratio}

The total noise in recorded spectra arises from photon or "shot" noise, optical noise and also instrumental noise. For a good DOAS instrument the photon noise should be the limiting factor in the achievable signal-to-noise ratio. In contrast to the other noise sources, photon noise is purely statistical and can therefore be reduced by accumulating more photons or co-adding multiple scans.

Since the detection limit of a DOAS instrument usually depends on the achievable signal-to-noise ratio (see Sect. 3), it is important to know whether and up to what degree the 


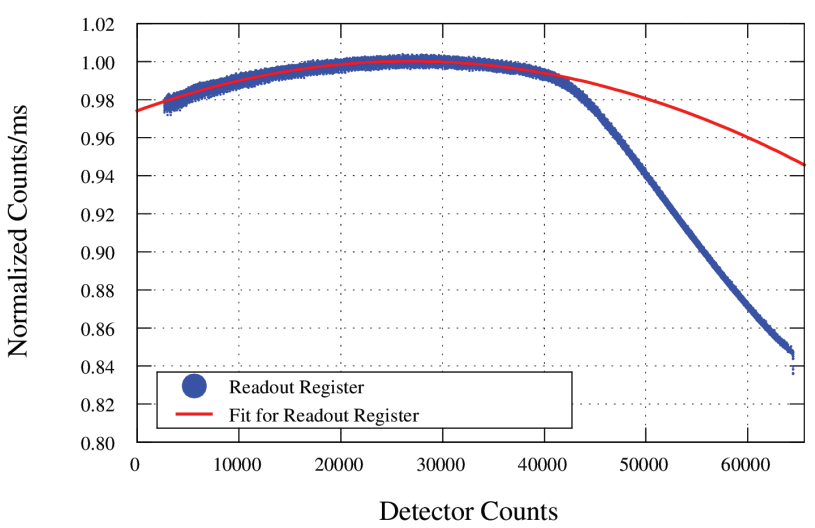

a) before linearization

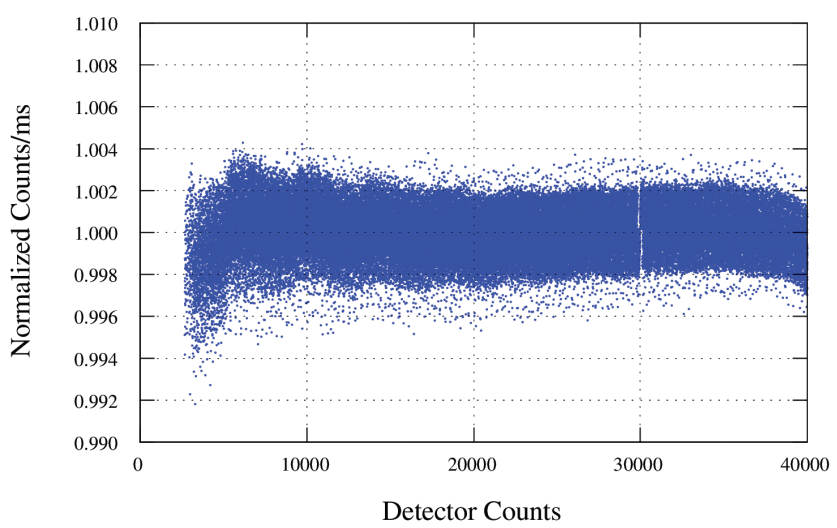

c) after linearization

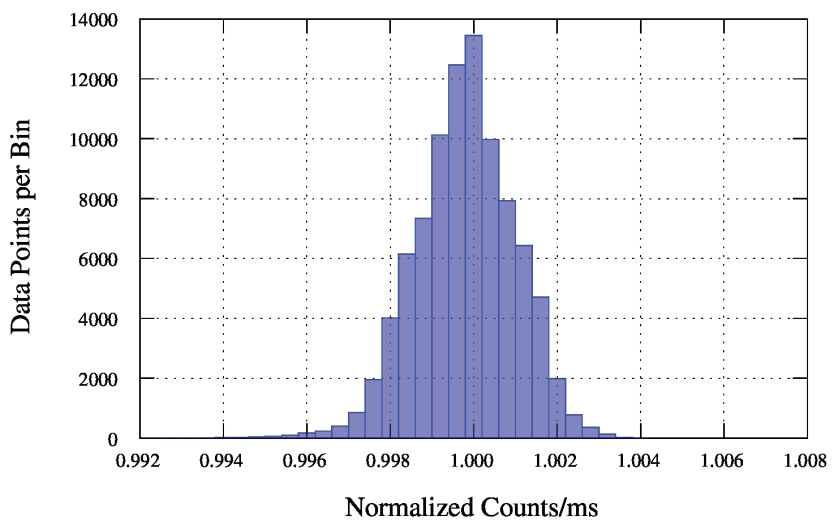

e) after linearization (histogram)

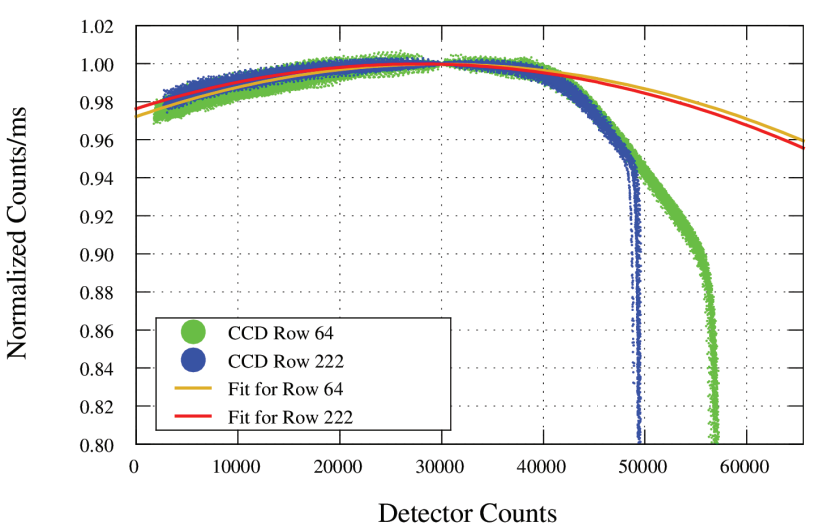

b) before linearization

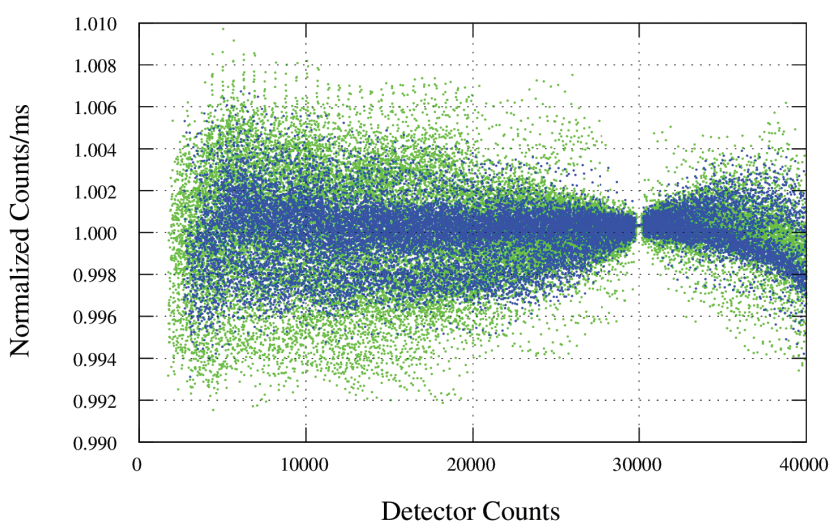

d) after linearization

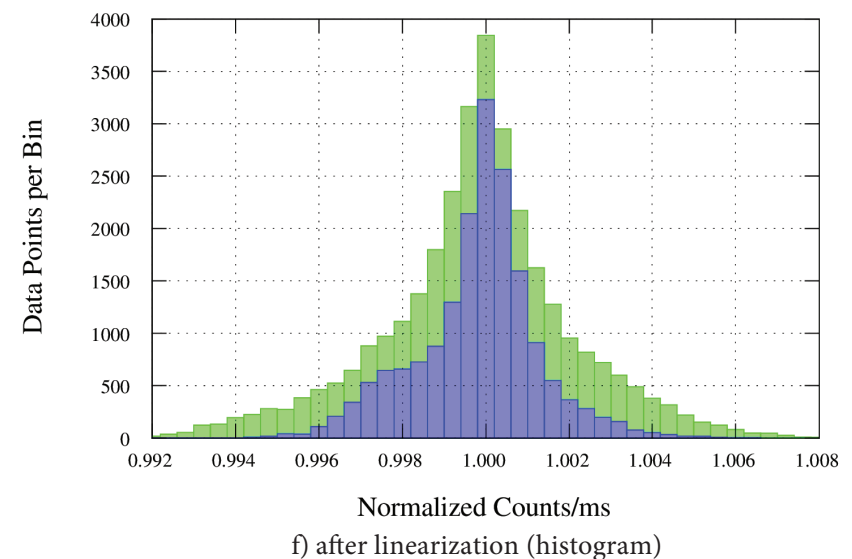

Figure 9. Results from a linearity test of HAIDI's detectors. The displayed counts ms are normalized to a reference value at an intensity level of 30000 counts. (a), (b) Measured counts per millisecond in full vertical binning (left) and full frame readout mode (right). (c), (d) Linearity of the analyzed pixel after correction by a second-order polynomial. (e), (f) Histogram of the corrected measurements.

noise in the spectra follows photon statistics. This can be determined by recording a large number of scans of a spectrally stable light source (e.g., halogen lamp) with the instrument. The scans should have the same exposure time and a saturation level which is preferably constant in time and over the considered part of the spectrum. Here we use scans with an integration time of $40 \mathrm{~ms}$ each and an average signal of 20000 counts, which approximately corresponds to $5 \times 10^{5}$ photons for the used detector. In order to access higher photon numbers, the recorded scans are co-added. The noise of two spectra $I_{1}, I_{2}$ with $k$ co-added scans is then calculated as follows:

Noise $[k]=\left[\ln \frac{I_{1}}{I_{2}}\right]_{\mathrm{HPF}=1000}$, 


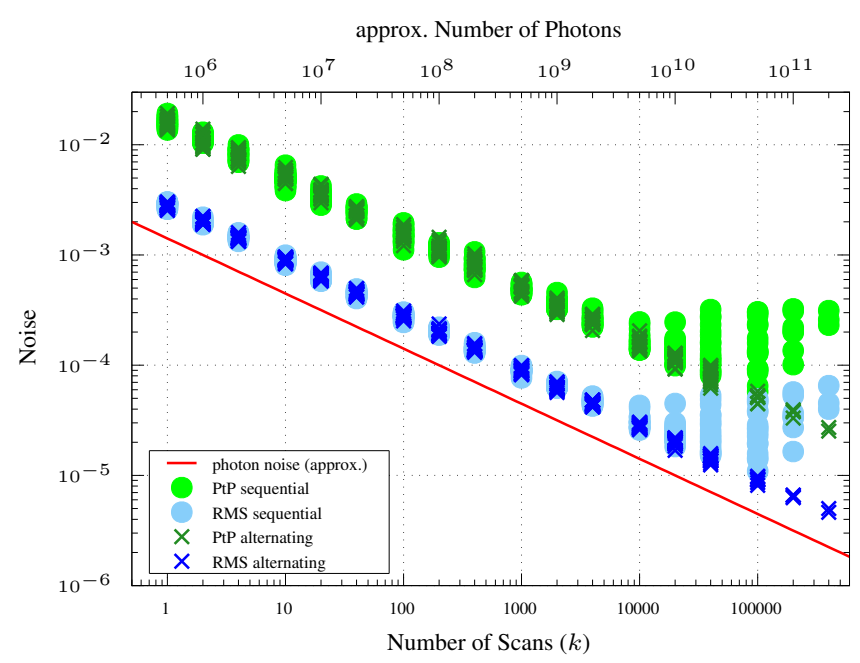

Figure 10. Results from a noise test of the HAIDI system plotted on a double-logarithmic scale. Scans with an integration time of $40 \mathrm{~ms}$ were co-added to get a larger number of photons (approximated values). The resulting noise is given as RMS and peak-topeak (PtP) value. For comparison also the pure photon noise (red curve) is plotted, which is given by the square root of the number of photons and represents the lowest achievable noise. The evaluation of the data was done in the wavelength region between 350 and $400 \mathrm{~nm}$.

where a binomial high pass filter (HPF) with 1000 iterations is applied to the logarithm in order to remove broadband structures. For co-adding the scans two different methods are used. In the first one (large dots, labeled "sequential" in Fig. 10), the number of photons in the spectra is increased by adding consecutive recorded scans $S_{n}$ :

$I_{1}=\sum_{n=1}^{k} S_{n}, \quad I_{2}=\sum_{n=1}^{k} S_{k+n}$.

As can be seen in Fig. 10, the root mean square (RMS) of the noise scales with photon statistics $\left(\frac{1}{\sqrt{N}}\right.$, red curve) first in this case, where $N$ is the number of incident photons. Starting at about 10000 scans (equivalent to $5 \times 10^{9}$ photons) other noise sources (e.g., readout noise, offset noise, dark current noise etc.) become dominant and the signal-tonoise ratio can not be improved any further by co-adding larger numbers of scans. In this method, however, timedependent effects play an important role. Since the spectra $I_{1}$ and $I_{2}$ consist of $k$ sequentially co-added scans, the time interval between the spectra equals the time to take $k$ scans, which is about $6.7 \mathrm{~min}$ for $k=10000$ and $4.4 \mathrm{~h}$ for $k=400000$. Within this time the instrument properties can slightly change, for example due to temperature changes. This effect can also be seen in Fig. 11, which shows the development of the noise with increasing temporal distance between spectra with $k=1000$.

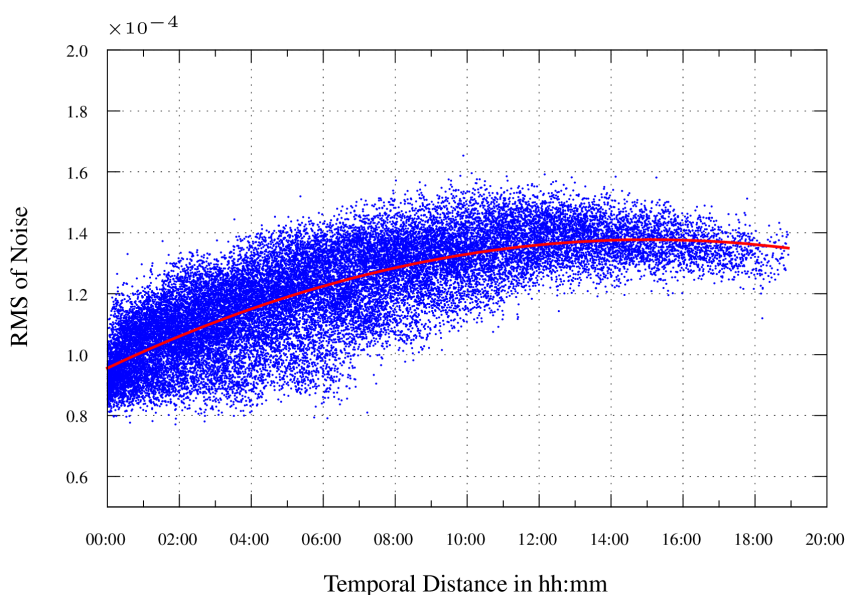

Figure 11. Development of the noise for spectra with 1000 coadded scans and increasing temporal distance. Within a few hours a slight increase in noise could be observed. Since photon noise does not change with time, the increase must have its origin in a changed instrument noise. The red line shows a polynomial fit of second order.

In a second evaluation, a different method for co-adding the recorded scans is performed to minimize these effects. Here, one spectrum consists of odd scans, while the other one encompasses the even scans:

$$
I_{1}=\sum_{n=1}^{k} S_{2 n}, \quad I_{2}=\sum_{n=1}^{k} S_{2 n-1} .
$$

Hence, the average time difference between the two spectra equals the time to record a single scan $(40 \mathrm{~ms})$. The result can also be seen in Fig. 10 (small crosses, labeled "alternating"). With this method the noise becomes much smaller at large numbers of co-added scans, since it is still following photon statistics up to the max. measured amount of 400000 scans or $2 \times 10^{11}$ photons.

\section{Data analysis}

\subsection{The DOAS evaluation}

The spectral data was analyzed for trace-gas absorptions by using the DOAS method (Platt and Stutz, 2008), which is implemented in the DOASIS software (Kraus, 2006). For the analysis, a Fraunhofer reference spectrum (FRS) and absorption cross sections of several trace gases are fitted simultaneously to the measurement spectra in a given wavelength region by a nonlinear least-squares fitting algorithm. The amount and type of fitted absorbers (Table 5) differ between the measurement campaigns due to different temperatures and different target trace gases. An overview of the used wavelength intervals and fitted absorbers can be found in Table 6. Apart from the listed absorbers, a Ring spectrum 
Table 5. List of trace gas references used for the DOAS analysis.

\begin{tabular}{lll}
\hline No. & Molecule & Reference \\
\hline 1 & $\mathrm{SO}_{2}(298 \mathrm{~K})$ & Vandaele et al. (2009) \\
2 & $\mathrm{BrO}(298 \mathrm{~K})$ & Fleischmann et al. (2004) \\
3 & $\mathrm{BrO}(243 \mathrm{~K})$ & Fleischmann et al. (2004) \\
4 & $\mathrm{NO}_{2}(246 \mathrm{~K})$ & Voigt et al. (2002) \\
5 & $\mathrm{NO}_{2}(293 \mathrm{~K})$ & Voigt et al. (2002) \\
6 & $\mathrm{O}_{3}(223 \mathrm{~K})$ & Voigt et al. (2001) \\
7 & $\mathrm{O}_{3}(246 \mathrm{~K})$ & Voigt et al. (2001) \\
8 & $\mathrm{O}_{3}(293 \mathrm{~K})$ & Voigt et al. (2001) \\
9 & $\mathrm{O}_{4}(293 \mathrm{~K})$ & Hermans et al. (1999) \\
10 & $\mathrm{HCHO}(298 \mathrm{~K})$ & Meller and Moortgat (2000) \\
11 & $\mathrm{OClO}(293 \mathrm{~K})$ & Kromminga et al. (1999) \\
\hline
\end{tabular}

(Grainger and Ring, 1962) calculated from the FRS by the DOASIS software, an inverse FRS (to reduce the offset due to stray light in the spectrometer), an additional Ring spectrum that is multiplied by $\lambda^{4}$ (to account for the wavelength dependency of the Ring effect, Wagner et al. (2009)), and a polynomial are fitted to the measured spectra.

In order to minimize the temporal distance between the reference and the actual measurement spectra, the FRS is normally taken for each flight, if possible. Thereby, the recording procedure differs for the two scanner types of the HAIDI system. While the nadir scanner uses a normal inflight measurement taken in a presumably clear area as reference, the forward-looking telescope uses a spectrum taken at the ground where sunlight is guided to the telescope with a sand blasted teflon plate. Because each viewing direction of a pushbroom scanner has a slightly different slit function, the forward-looking telescope uses a separate FRS for each elevation angle. The nadir scanner instead has the same slit function for all viewing directions and therefore uses a single FRS for the analysis of the spectral data.

All measurement flights up to now were done in smaller, unpressurized aircraft and HAIDI's spectrographs were also not pressure stabilized during these flights. Therefore, a wavelength shift of the measured spectra in dependency of the flight altitude could be observed, due to pressure-induced changes in the refractive index of air. The observed values for the shift are linear with respect to the measured change in ambient pressure and are in the order of $1 \times 10^{-4} \mathrm{~nm} \mathrm{mbar}^{-1}$, which is in very good agreement with the theoretical value of $0.988 \times 10^{-4} \mathrm{~nm} \mathrm{mbar}^{-1}$ at $350 \mathrm{~nm}$. During the BROMEX campaign, flight altitudes of up to $3300 \mathrm{~m}$ were reached with a pressure difference of about $380 \mathrm{mbar}$ in total, which means a shift of approx. $0.04 \mathrm{~nm}$ compared to spectra taken close to the ground. In order to obtain better initial conditions for the DOAS fit, each measurement spectrum is previously shifted according to its pressure difference from the FRS. Since an initial wavelength calibration of the two instruments is done with the help of mercury emission lines on the ground but the reference spectrum is taken somewhere in flight, the
Fraunhofer reference is re-calibrated using a high resolution solar spectrum (Kurucz et al., 1984) at the beginning of the evaluation procedure.

The residual spectrum of a DOAS analysis indicates the quality of the measured spectra and the spectral analysis (Stutz, 1996). Some exemplary fit results with corresponding residual spectra are illustrated in Figs. 12 and 13. For a DOAS analysis free of systematic effects the size of the residual structures should mainly depend on the number of incident photons and therefore on the number of co-added spectra. The calculated photon noise in Fig. 10 is therefore the best achievable value for the RMS of the residual. However, for atmospheric measurements the size of the residual structures will usually deviate earlier from the values predicted by photon noise. This can be due to various reasons, a not perfectly uniform illuminated entrance slit, spectral structures caused by different ground surfaces and viewing directions, a suboptimal fit scenario or imperfect reference spectra. In Table 7 the size of the residual structure as well as the achieved detection limit is listed for different numbers of co-added scans. The measurement errors $(1 \sigma)$ and detection limits $(2 \sigma)$ are calculated from the DOAS fit results according to Stutz and Platt (1996). Accordingly, the fit error is multiplied by 2 to obtain the $1 \sigma$ measurement error. Since increasing the number of co-added scans will degrade the spatial resolution of the HAIDI system, a compromise between detection limit and spatial resolution has to be made depending on the optical density of the trace gas of interest.

\subsection{Geometrical approximation of the light path}

The result of a DOAS analysis is the so-called differential slant column density (dSCD), $S^{\prime}$, which is the concentration of the trace gas integrated along a particular light path through the atmosphere minus the integrated concentration already existing in the FRS. As the light path through the absorber depends on the respective measurement conditions (e.g., measurement geometry, solar zenith angle (SZA, $\theta$ ), cloudiness), the dSCDs are usually converted to vertical column densities (VCDs), $V$, which give the concentration along a vertical path through the atmosphere and therefore are independent of the used viewing direction. This is commonly done by applying radiative transfer models (RTMs). However, for certain conditions, like high surface albedo, cloud free sky, $\mathrm{SZA} \leq 80^{\circ}$ and low flight altitude, the light path can also be estimated by a more simple geometric approximation. These conditions are largely met by the nadir measurements presented in this article. The following thus shows a geometric consideration of the nadir scanner's light path, as well as an approach for the conversion of dSCDs to tropospheric VCDs. Even if the geometric approximation is a strong simplification which may cause errors (e.g., Berg et al., 2012; Baidar et al., 2013) and RTM could give more precise results, it still has some advantages. It is very fast and 
Table 6. List of fitted absorbers and selected wavelength intervals. In Italy two different fit ranges for $\mathrm{SO}_{2}$ were applied, due to non-linearity at high optical densities (Kern et al., 2010; Bobrowski et al., 2010).

\begin{tabular}{|c|c|c|c|c|}
\hline Target trace gas & $\begin{array}{l}\text { Wavelength } \\
\text { range in } \mathrm{nm}\end{array}$ & Fitted absorber & $\begin{array}{l}\text { Polynomial } \\
\text { order }\end{array}$ & Campaign \\
\hline $\mathrm{SO}_{2} \quad\left(\mathrm{dSCD}<5 \times 10^{17} \mathrm{molec}^{-2}\right)$ & $310.0 \ldots 322.0$ & $1,2,5,6,8,10$ & 3 & \\
\hline $\mathrm{SO}_{2} \quad\left(\mathrm{dSCD} \geq 5 \times 10^{17} \mathrm{molec}^{-2}\right)$ & $314.8 \ldots 326.8$ & $1,2,5,6,8,10$ & 3 & Italy 2011 \\
\hline $\cos$ & $332.8 \ldots 364.0$ & $1,2,5,6,8,9,10,11$ & 3 & 1 taly 2011 \\
\hline $\mathrm{NO}_{2}$ & $358.0 \ldots 387.0$ & $1,5,9,11$ & 3 & \\
\hline $\mathrm{NO}_{2}$ & $358.0 \ldots 387.0$ & 5,9 & 3 & $\begin{array}{l}\text { USA } 2011 \\
\text { (Indiana) }\end{array}$ \\
\hline $\mathrm{BrO}$ & $336.0 \ldots 365.0$ & $3,4,6,7,9,10$ & 3 & USA 2012 \\
\hline $\mathrm{NO}_{2}$ & $358.0 \ldots 387.0$ & 4,9 & 3 & (Barrow) \\
\hline
\end{tabular}

Table 7. Influence of scan binning on the spatial resolution and detection limit of the nadir scanner (whiskbroom). The first value of the binning is the amount of included swaths, while the second value gives the number of co-added scans within each of these swaths. The spatial resolution $\left(P_{\|} \times P_{\perp}\right)$ is calculated by Eqs. (1) and (2) for average flight conditions $\left(h_{\text {a.g.l. }}=1500 \mathrm{~m}, v_{\mathrm{g}}=55 \mathrm{~m} \mathrm{~s}{ }^{-1}\right)$. The spectra for determining the detection limits were taken from the same time intervals as the fits shown in Figs. 12 and 13.

\begin{tabular}{llllll}
\hline Trace gas & $\begin{array}{l}\text { Scan } \\
\text { binning }\end{array}$ & $\begin{array}{l}\text { Spatial resolution } \\
\text { per pixel in } \mathrm{m}\end{array}$ & $\begin{array}{l}\text { Total integration } \\
\text { time in s }\end{array}$ & RMS of residual & $\begin{array}{l}\text { Detection limit in } \\
\text { molec cm }^{-2}\end{array}$ \\
\hline $\mathrm{BrO}$ & $1 \times 8$ & $39 \times 137$ & 0.2 & $5.41 \times 10^{-4}$ & $7.04 \times 10^{13}$ \\
$\mathrm{BrO}$ & $2 \times 16$ & $181 \times 234$ & 0.6 & $2.78 \times 10^{-4}$ & $3.63 \times 10^{13}$ \\
$\mathrm{BrO}$ & $4 \times 16$ & $465 \times 234$ & 1.3 & $2.24 \times 10^{-4}$ & $2.93 \times 10^{13}$ \\
$\mathrm{BrO}$ & $4 \times 32$ & $465 \times 429$ & 2.6 & $1.89 \times 10^{-4}$ & $2.47 \times 10^{13}$ \\
$\mathrm{NO}_{2}$ & $1 \times 8$ & $39 \times 137$ & 0.2 & $6.08 \times 10^{-4}$ & $5.60 \times 10^{15}$ \\
$\mathrm{NO}_{2}$ & $2 \times 16$ & $181 \times 234$ & 0.6 & $3.77 \times 10^{-4}$ & $3.47 \times 10^{15}$ \\
$\mathrm{NO}_{2}$ & $4 \times 16$ & $465 \times 234$ & 1.3 & $3.34 \times 10^{-4}$ & $3.07 \times 10^{15}$ \\
$\mathrm{NO}_{2}$ & $4 \times 32$ & $465 \times 429$ & 2.6 & $3.06 \times 10^{-4}$ & $2.81 \times 10^{15}$ \\
\hline
\end{tabular}

relatively simple to calculate, it does not depend on a priori values, and it gives a robust output.

\subsubsection{Nadir observations}

Under the assumption that the majority of the detected photons are only once scattered on the ground (or very close to it) before entering the instrument and that the tropospheric absorber layer is horizontally homogeneously distributed on scales of a few hundred meters, there are three possible measurement scenarios for the nadir scanner. Either the aircraft is located above the absorber layer (Fig. 14a), within the absorber layer (Fig. 14b) or below the absorber layer (Fig. 14c). In each of these cases the length of the light path changes as a function of solar zenith angle $\theta$, scan angle $\beta$ and aircraft roll angle $\varphi$ (see Fig. 14). The factors $A_{1}$ and $A_{2}$ thereby express the extension of the actual light path relative to a vertical one and thus represent a proportionality factor between observed slant column densities and VCDs, the so-called air mass factor (AMF), $A=\frac{S}{V} . A_{1}$ and $A_{2}$ are given by the following equations:

$$
\begin{aligned}
& A_{1} \approx \frac{1}{\cos \theta} \\
& A_{2} \approx \frac{0 . .1}{\cos (\beta-\varphi)} .
\end{aligned}
$$

The numerator of $A_{2}$ depends on the position of the aircraft in relation to the absorber layer and ranges from 1 (above the absorber) to 0 (below the absorber). The total extension of the light path in the troposphere is then given by the following equation:

$A_{\text {trop }}=A_{1}+A_{2}$.

The scenario where the aircraft is located above the absorber (Fig. 14a) can be applied in good approximation to the measurement campaigns II and III (see Table 1). Here, the trace gas layers were expected to be within the planetary boundary layer and thus below the typical flight altitude of the aircraft equipped with HAIDI. This could also be confirmed by the data from the forward-looking DOAS system. Hence, the tropospheric AMF assumed for the measurements presented in Sect. 6.3 was calculated as follows: 


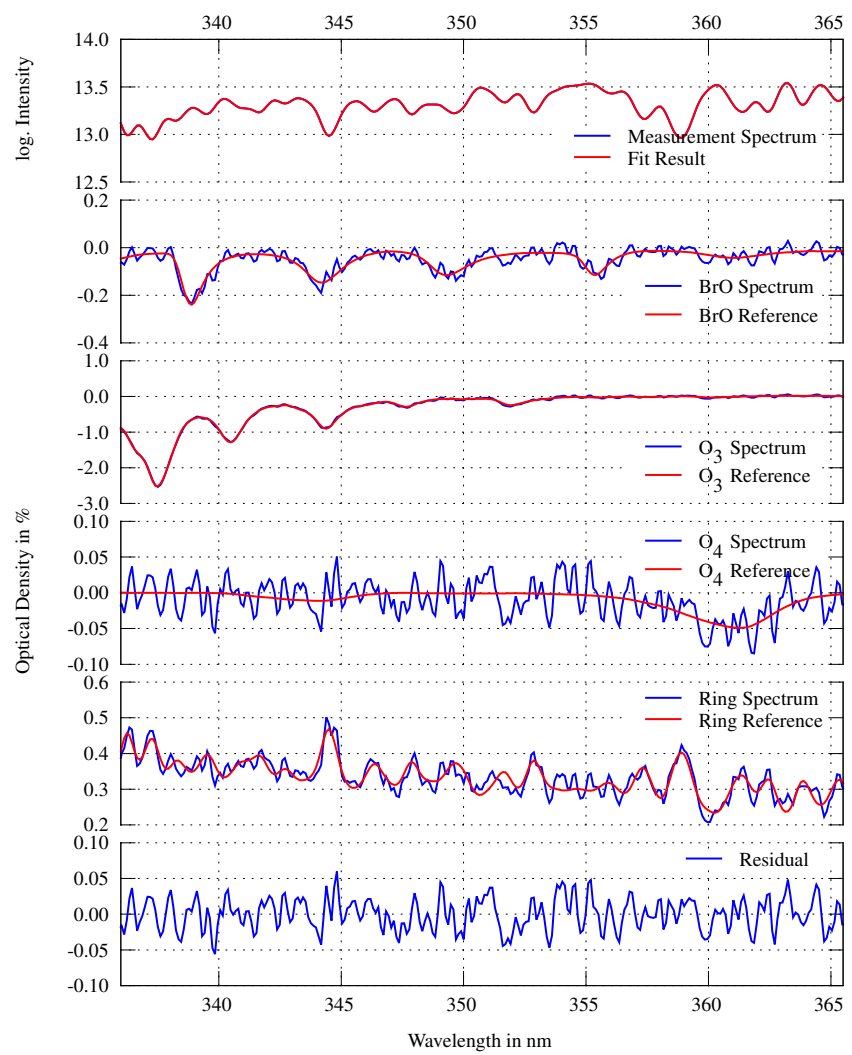

Figure 12. Sample $\mathrm{BrO}$ fit $\left(\mathrm{dSCD} \approx 1.6 \times 10^{14} \mathrm{molec}^{-2}\right)$ of a nadir measurement taken from the flight to Prudhoe Bay on 31 March 2012 at 02:05 UTC. The red line shows the fitted absorption structure whereas the blue line shows the fit result plus the residual.

$A_{\text {trop }}=\frac{1}{\cos \theta}+\frac{1}{\cos (\beta-\varphi)}$.

For the flights at Mt. Etna instead, where the absorber layer was not located close to the ground, this is not generally the case. Here, one has to distinguish between measurements taken above the emission plume and those taken below. Due to the smaller AMF (see Eq. 8), measurements from below the plume show smaller dSCDs. In addition, the changed measurement geometry (see Fig. 14) can cause a significant spatial shift of the measured signal as a function of the solar zenith and azimuth angles, because the light traverses the absorption layer far from the surface reflection. Thus, for a better comparability, maps presented from Mt. Etna in Sect. 6.1 show only data for flight altitudes greater than the expected height of the emission plume.

\subsubsection{Conversion of dSCDs to tropospheric VCDs}

In order to convert dSCDs to tropospheric VCDs, one has to consider that the observed signal does not only arise from tropospheric absorbers. Many of the fitted trace gases are also

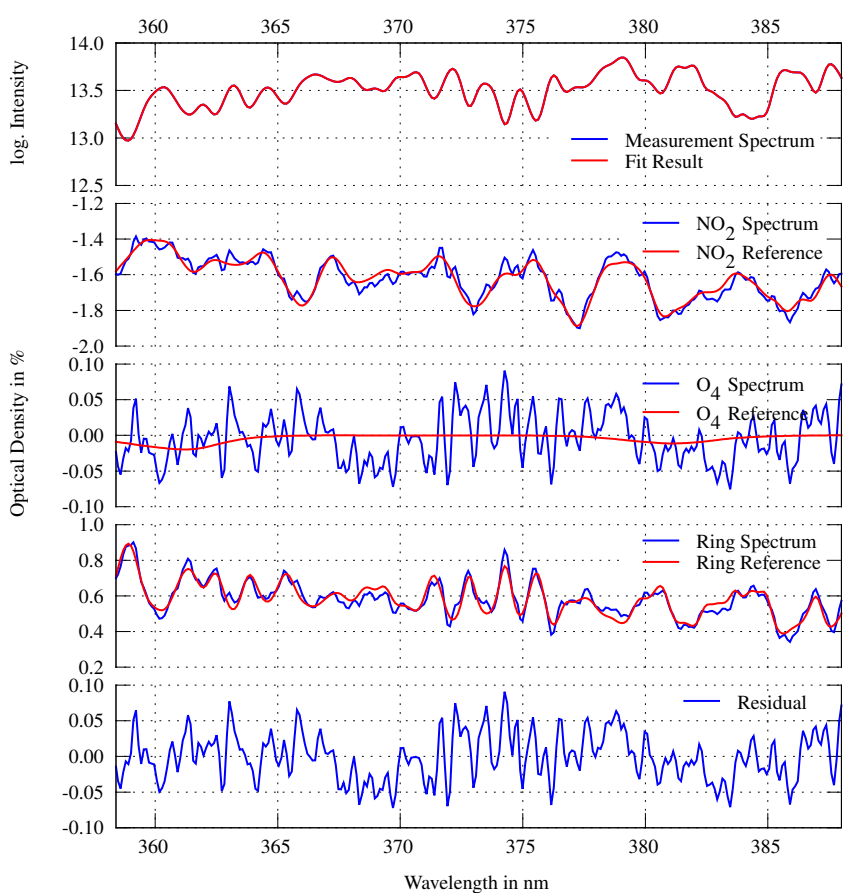

Figure 13. Sample $\mathrm{NO}_{2}$ fit $\left(\mathrm{dSCD} \approx 3.1 \times 10^{16}\right.$ molec $\left.\mathrm{cm}^{-2}\right)$ of a nadir measurement taken from the flight to Prudhoe Bay on 31 March 2012 at 01:58 UTC. The red line shows the fitted absorption structure whereas the blue line shows the fit result plus the residual.

present in the stratosphere. Since the flight altitude of an unpressurized aircraft will not reach the height of stratospheric absorbers, the stratospheric AMF remains unchanged for all three measurement scenarios described in the previous section. The stratospheric AMF, $A_{\text {strat }}$, therefore only depends on the SZA and can be approximated similar to $A_{1}$ in the troposphere:

$A_{\text {strat }}=\frac{1}{\cos \theta}$.

Before $A_{\text {trop }}$ and $A_{\text {strat }}$ can be used to convert the measured dSCDs, $S^{\prime}$, to tropospheric VCDs, one first has to make clear that the column density in the measurement spectra is composed as follows:

$$
\begin{aligned}
S^{\prime} & =S_{\text {trop }}^{\prime}+S_{\text {strat }}^{\prime} \\
& =\underbrace{S_{\text {trop }}-S_{\text {Ref, trop }}}_{S_{\text {trop }}^{\prime}}+\underbrace{S_{\text {strat }}-S_{\text {Ref, strat }}}_{S_{\text {strat }}^{\prime}},
\end{aligned}
$$

where $S_{\text {trop }}$ is the tropospheric slant column density (SCD) in the measurement, $S_{\text {Ref, trop }}$ the tropospheric SCD in the Fraunhofer reference, $S_{\text {strat }}$ the stratospheric SCD and $S_{\text {Ref, strat }}$ the stratospheric part of the SCD in the Fraunhofer reference. The relative change in stratospheric SCD, $S_{\text {strat }}^{\prime}$, 


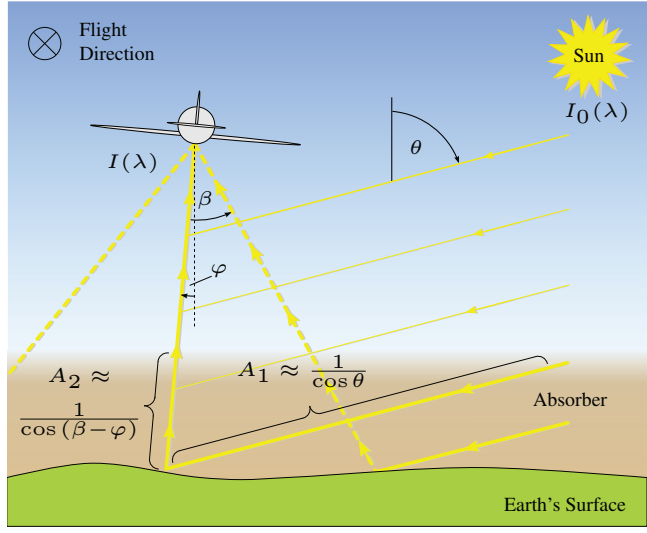

(a) aircraft above absorber

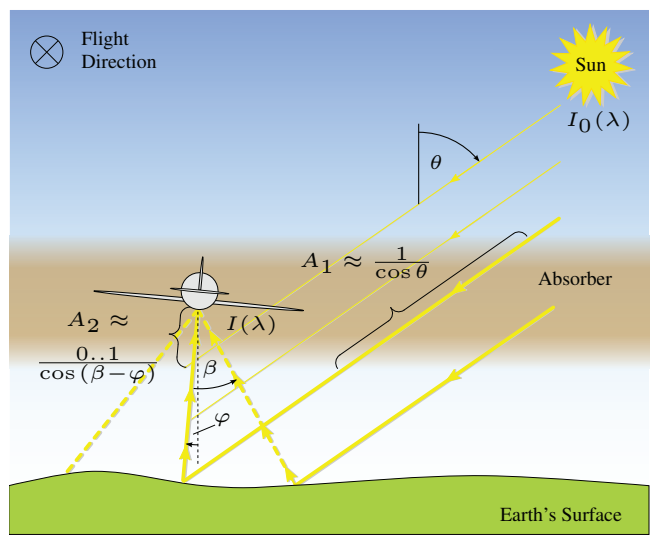

(b) aircraft within absorber

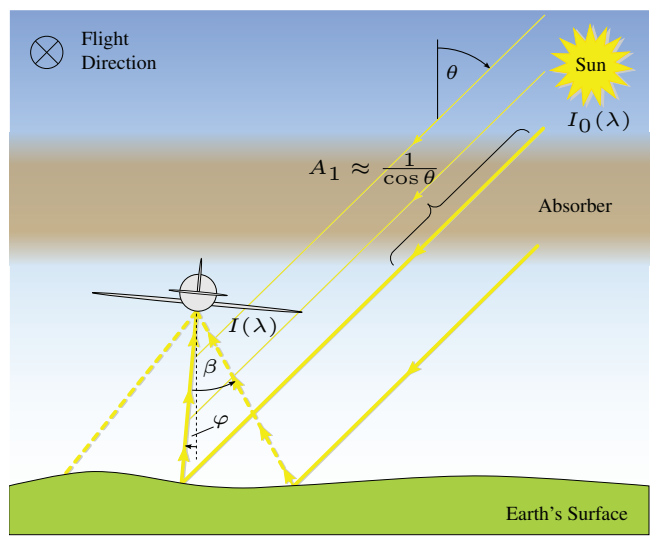

(c) aircraft below absorber

Figure 14. Simple geometric approximation of the optical light path for the nadir scanner. Due to clear sky conditions and low flight altitudes $(\sim 1500 \mathrm{~m})$ most of the collected light is scattered on the ground. The length of the optical light path inside the absorber is determined by the factors $A_{1}$ and $A_{2}$.

can then be expressed by the stratospheric AMF:

$$
\begin{aligned}
S_{\text {strat }}^{\prime} & =S_{\text {strat }}-S_{\text {Ref, strat }} \\
& =V_{\text {strat }} \times A_{\text {strat }}-V_{\text {Ref, strat }} \times A_{\text {Ref, strat }}
\end{aligned}
$$

By assuming that the stratospheric VCD remains relatively constant during the flight (which is a realistic approximation for $\mathrm{BrO}$ and $\mathrm{NO}_{2}$ at $\mathrm{SZA} \leq 80^{\circ}$ ), and that $V_{\text {strat }}$ and $V_{\mathrm{Ref}}$, strat are therefore identical, one obtains the following:

$S_{\text {strat }}^{\prime}=V_{\text {strat }} \times\left(A_{\text {strat }}-A_{\text {Ref, strat }}\right)$,

and thus,

$$
\begin{aligned}
S^{\prime} & =V_{\text {trop }} \times A_{\text {trop }}-\underbrace{V_{\text {Ref, trop }} \times A_{\text {Ref, trop }}}_{\approx 0} \\
& +V_{\text {strat }} \times\left(A_{\text {strat }}-A_{\text {Ref, strat }}\right) .
\end{aligned}
$$

With a careful selection of the Fraunhofer reference spectrum, $V_{\text {Ref, trop }}$ can be assumed to be 0 . A candidate for such a FRS can be a spectrum taken upwind of an emission source. Also a zero VCD obtained from the forward-looking telescope is an indicator for a potential FRS. The above equation can finally be rearranged to $V_{\text {trop }}$ :

$\Rightarrow V_{\text {trop }}=\frac{S^{\prime}-V_{\text {strat }} \times\left(A_{\text {strat }}-A_{\text {Ref, strat }}\right)}{A_{\text {trop }}}$.

The required stratospheric VCD of the absorber can then be obtained from model calculations or reference data, if available. As mentioned above the geometric approximation (Eq. 16) is only valid for certain conditions, which are fulfilled, however, for the majority of the presented measurements. If in these cases, the error from the stratospheric correction and the tropospheric AMF are relative small in comparison to the error of the slant column density $\Delta S^{\prime}$, then the error of $V_{\text {trop }}$ can be approximated by the following:

$\Delta V_{\text {trop }} \approx \frac{\Delta S^{\prime}}{S^{\prime}} \times V_{\text {trop }}$.

For a more precise error estimation, RTM calculations are necessary.

\subsubsection{Limb observations}

For a telescope looking towards the horizon (limb geometry), the geometrical AMF would lead to significant deviations, because in contrast to the nadir observations it cannot be assumed here that the majority of the collected light is scattered at a given location. Instead light is scattered into the telescope from somewhere along its line of sight (LOS). Under clear sky conditions most direction changes of light are induced by Rayleigh scattering on air molecules. Thus, due to typical Rayleigh extinction lengths of about $14 \mathrm{~km}$ at $350 \mathrm{~nm}$, very long light paths can be obtained within horizontally extended absorbers.

Limb observations performed at different flight altitudes are particularly well suited for a reconstruction of trace gas and aerosol profiles at high vertical resolution (e.g., Heue et al., 2011; Prados-Roman et al., 2011; Merlaud et al., 2012; 


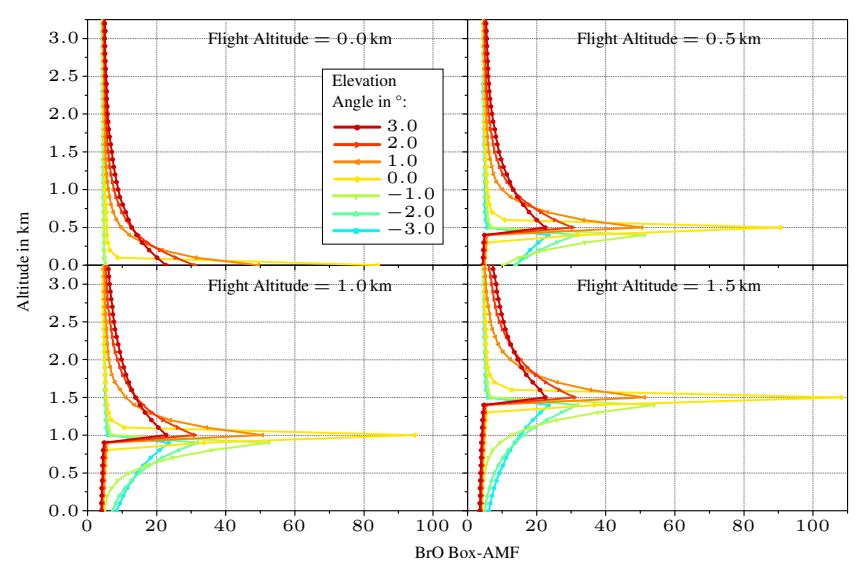

Figure 15. BrO box AMFs calculated for the different viewing directions of HAIDI's forward-looking telescope.

Baidar et al., 2013; Dix et al., 2013). This is usually done in a two-stage process using inverse modeling of the atmospheric radiative transfer (e.g., Sinreich et al., 2005; Wagner et al., 2004; Frieß et al., 2006; Irie et al., 2008; Clémer et al., 2010; Wagner et al., 2011). First, the aerosol extinction profile is retrieved from the absorption of the oxygen collision complex $\mathrm{O}_{4}$, which has a horizontally constant atmospheric concentration (apart from pressure variations) and therefore serves as a proxy of the light path which is affected by aerosols. Second, the trace gas vertical profile is retrieved using the measured trace gas dSCDs together with the aerosol profile retrieved in the first step. Resting upon the Bayesian approach, our retrieval algorithms determine the maximum a posteriori solutions of the given inverse problems on the basis of the well-known optimal estimation method (Rodgers, 2000) and use the SCIATRAN (Rozanov et al., 2001) and McArtim (Deutschmann et al., 2011) radiative transfer code as forward models for the aerosol and trace gas retrievals, respectively. This method has been applied e.g., to ground-based MAXDOAS measurements of $\mathrm{BrO}$ and aerosols in the scope of the OASIS Barrow 2009 campaign (Frieß et al., 2011).

A key quantity that describes the accuracy of the profile retrieval is the weighting function $\mathbf{K}=\partial \boldsymbol{y} / \partial \boldsymbol{x}$, which represents the sensitivity of the measurement $\boldsymbol{y}$ to variations of the state vector (i.e., aerosol or trace gas vertical profile) $\boldsymbol{x}$. In case of trace gas profiles, the weighting function is equal to the box air mass factor, i.e., the derivative of the measured slant column density with respect to the partial vertical column in an altitude layer $[z, z+\Delta z]$. Figure 15 shows $\mathrm{BrO}$ box AMFs calculated at a wavelength of $350 \mathrm{~nm}$ for a small aerosol extinction of $0.01 \mathrm{~km}^{-1}$ between surface and $1 \mathrm{~km}$ altitude and zero above for the viewing geometry of the HAIDI limb telescope. The calculations were performed for flight altitudes of $0,0.5,1$ and $1.5 \mathrm{~km}$. As expected, the highest sensitivity for trace gases is achieved directly at the flight altitude when looking towards the horizon (elevation angle of $0^{\circ}$ ), here the box-AMF reaches values of more than
Table 8. Approximate weights and dimensions of the different HAIDI configurations. The first two configurations have an average power consumption of about $100 \mathrm{~W}$, while the HALO setup consumes slightly more due to the additional spectrograph-detector unit.

\begin{tabular}{lllr}
\hline Aircraft & Weight & Dimensions & \\
\hline CTLS & \multirow{2}{*}{$15 \mathrm{~kg}$} & Detectors + & \\
& & Spectrographs: & $25 \times 25 \times 37 \mathrm{~cm}$ \\
& & Computers: & $26 \times 19 \times 6 \mathrm{~cm}$ \\
\hline \multirow{2}{*}{ ALAR } & \multirow{2}{*}{$40 \mathrm{~kg}$} & HAIDI Rack: & $48 \times 50 \times 27 \mathrm{~cm}$ \\
& & Entrance Optics: & $18 \times 10 \times 18 \mathrm{~cm}$ \\
& & Computers: & $48 \times 50 \times 11 \mathrm{~cm}$ \\
\hline HALO & \multirow{2}{*}{$65 \mathrm{~kg}$} & HAIDI Rack: & $48 \times 50 \times 27 \mathrm{~cm}$ \\
& & Entrance Optics: & $25 \times 18 \times 15 \mathrm{~cm}$ \\
& & Computers: & $48 \times 50 \times 11 \mathrm{~cm}$ \\
\hline
\end{tabular}

100. With viewing directions covering $\pm 3^{\circ}$, the range where measurements are sensitive is restricted to about $1 \mathrm{~km}$ around the flight altitude. Thus, measurements with the forwardtelescope (pushbroom) are especially suited for the observation of volcanic plumes close to the flight altitude (Vogel et al., 2011), or to investigate boundary layer absorbers when flying low. A reconstruction of the whole tropospheric profile (surface to $10 \mathrm{~km}$ ) is only possible when measurements during a whole ascent or descent of the airplane are used as input for the retrieval.

\section{Measurement software}

Because of the custom-made readout electronics of HAIDI's CCD detectors, a software had to be written, that is able to communicate with the hardware. This software allows one to control the thermoelectric cooling of the detector, the movement of the nadir scanner (whiskbroom) and other parameters of the camera like the integration time or co-adding of scans. Moreover, it reads out the recorded spectra from the electronics via USB connection and stores them in a specific directory structure for later easy access. The current version of the software is written in LabVIEW 2013 and can be used with Windows XP or higher.

To handle the high rate of spectra generated by the nadir scanner (up to 100 spectra per second), all spectra taken during one swath are buffered inside the camera electronics first. After the last spectrum of a swath is taken, the measurement software starts to read out the data and stores it into a single file per swath. This significantly reduces the access frequency of the data storage device (HDD or SD-card). While the data is transfered to the computer, the scanner can already start to record a new swath. 

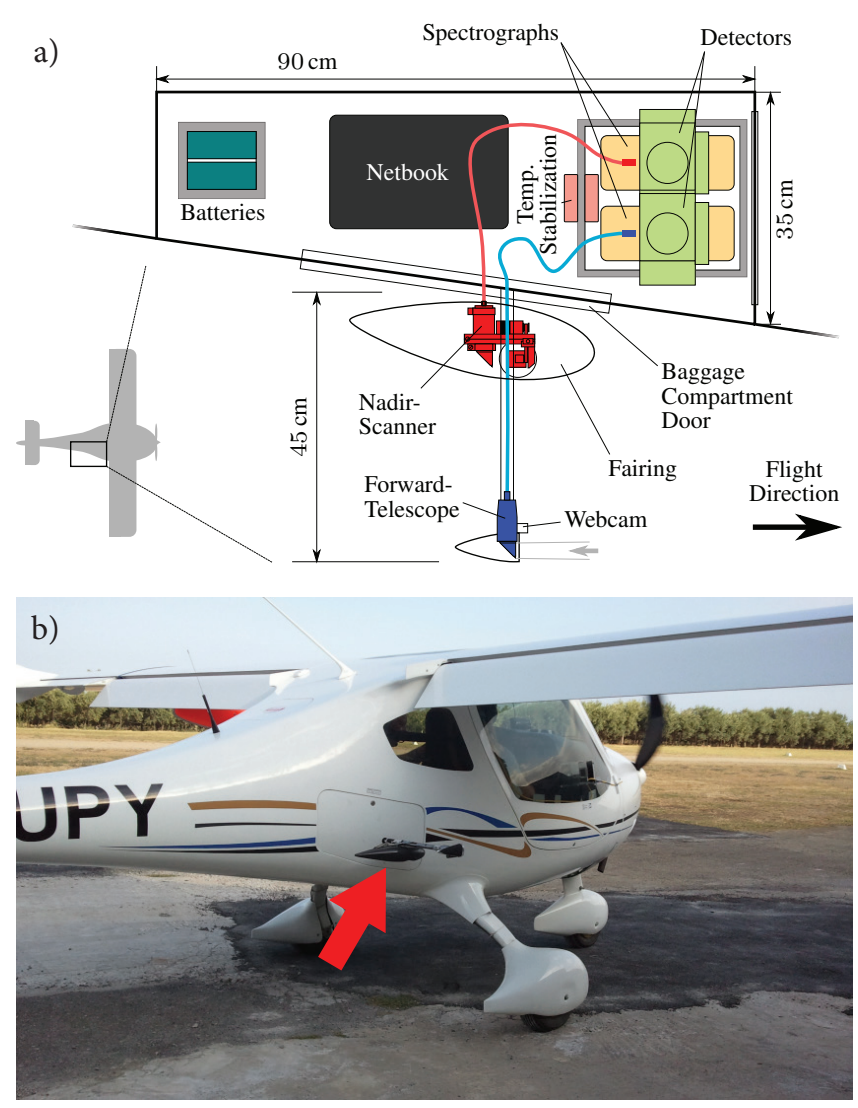

Figure 16. Installation of HAIDI on an ultralight aircraft during the measurements on Sicily, Italy. (a) top view sketch of the CTLS baggage compartment with HAIDI installed. The entrance optics of the instrument are located outside the aircraft. While the nadir scanner (red) is placed close to the aircraft fuselage, the forwardlooking telescope (blue) is mounted to an extension arm to get a free line of sight. (b) Picture of the CTLS showing the location of the entrance optics (red arrow).

\section{Measurement platforms}

HAIDI was developed for operation on the new German research aircraft HALO (High Altitude and Long Range Research Aircraft), where an instrumental setup with three whiskbroom scanners (Sect. 2.3) pointed to different directions will be used. This setup is optimized for high altitude flights. However, besides applications on HALO the system can also be operated on other aircraft. Measurement flights on smaller aircraft were performed in order to optimize the system in preparation of the installation on HALO. These aircraft fly at lower altitude and usually do not offer sufficient space and power to operate three whiskbroom scanners simultaneously. Furthermore, a setup with three whiskbroom scanners will not allow to retrieve accurate altitude information of absorbers when flying too low. For these reasons, the instrumental setup was modified in such a way that it requires less space and power, but still provides the possibility
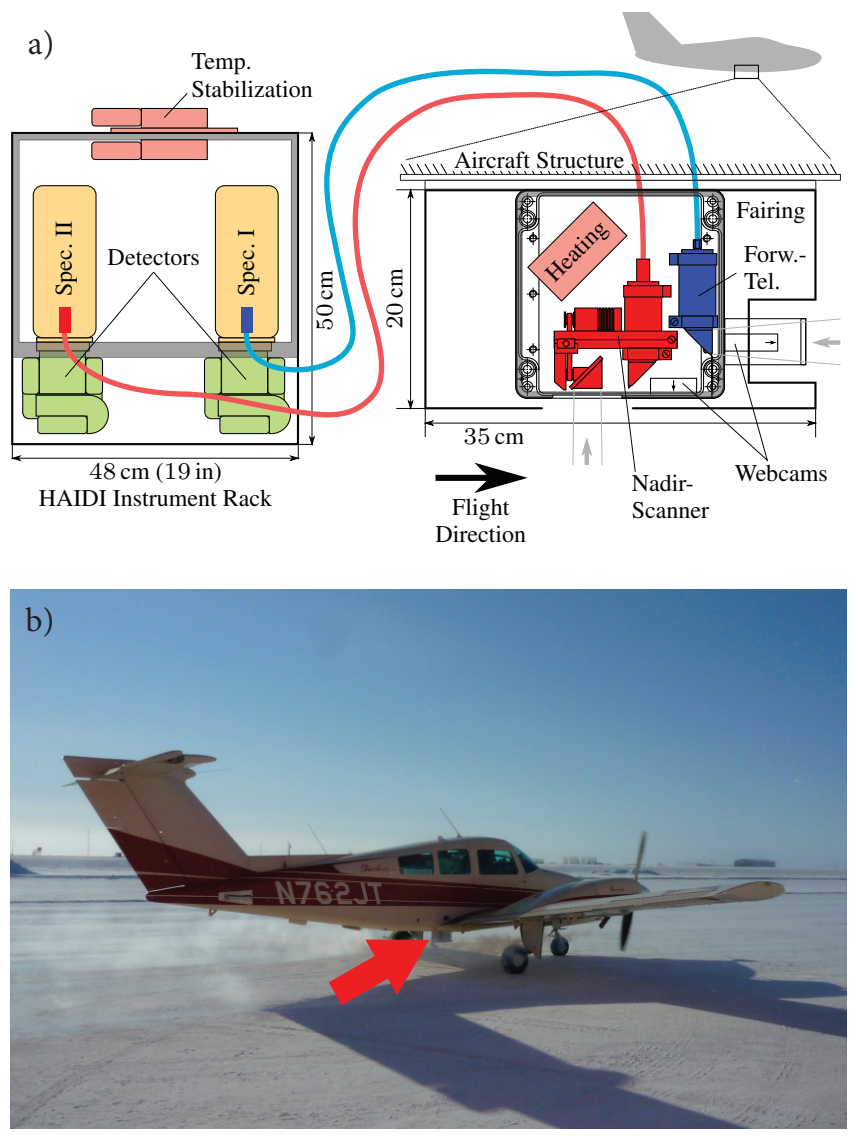

Figure 17. Instrumental setup for measurement flights with the ALAR research aircraft from Purdue University. (a) Sketch showing HAIDI's instrument rack and the aluminum box with the entrance optics. Each viewing direction is equipped with additional webcams to record weather and surface conditions. (b) ALAR research aircraft with HAIDI installed. The red arrow is pointing to the box with the entrance optics of the instrument, which is connected to the spectrographs and detectors inside the aircraft via fiber optic cables going through the fuselage of the aircraft.

to retrieve horizontal distributions and vertical profiles. This altered setup uses only a single whiskbroom scanner in nadir direction and in addition a forward-looking telescope, using the pushbroom technique (Sect. 2.4). In the following, the instrumental setups used for the different aircraft are described. Approximate weights and dimensions of these setups can be found in Table 8.

\subsection{Setup for Flight Design CTLS Ultralight Aircraft}

The first measurement flights with the HAIDI system were performed in July 2011 on Sicily (Italy) with a small ultralight aircraft (Flight Design CTLS) operated by the FH Düsseldorf (Sect. 6.1). Because of the compactness and weight limitations of such an aircraft there was only very limited storage space available for the installation of the system. In order to save as much space as possible an instrument rack 
Table 9. List of flights from which data is presented in this article.

\begin{tabular}{lllll}
\hline Location & Date & Flight Duration (UTC) & Flight Duration (LT) & SZA in $^{\circ}$ \\
\hline Mt. Etna, Sicily (Italy) & $09 / 07 / 2011$ & $08: 00-10: 30$ & $10: 00-12: 30$ & $42 \ldots 17$ \\
Indianapolis, Indiana (USA) & $24 / 10 / 2011$ & $16: 31-19: 00$ & $12: 31-15: 00$ & $54 \ldots 56$ \\
Prudhoe Bay, Alaska (USA) & $31 / 03 / 2012$ & $00: 25-03: 45$ & $16: 25-19: 45$ & $69 \ldots 82$ \\
\hline
\end{tabular}

was omitted here. Instead, the spectrographs were directly put in a temperature stabilized case of PE-foam (MP15FR from Wulfmeyer) and placed in the baggage compartment of the aircraft.

Because of the forward-looking viewing direction and the lack of optical viewports, HAIDI's entrance optics had to be placed somewhere outside the aircraft. For this reason, a steel frame, holding a carbon fiber tube of $20 \mathrm{~mm}$ diameter, was mounted inside the aircraft's baggage compartment. The tube went through a hole in the baggage compartment door on the starboard side (see Fig. 16) and protruded about $45 \mathrm{~cm}$ from the aircraft fuselage. The forward-looking telescope and a webcam (resolution of $640 \times 480$ pixel) were attached at the end of that tube in order to get a clear line of sight, past the propeller. The nadir scanner instead was located close to the aircraft fuselage in an aerodynamic housing, to keep the load on the carbon tube as small as possible. Due to the short distance between spectrograph and entrance optics of the nadir scanner, the mono fiber used here was only $19 \mathrm{~cm}$ in length. Beside the spectrographs and detectors, also a netbook for system control and data storage as well as a lithium-polymer battery pack $(20 \mathrm{~A} \mathrm{~h}, 14.8 \mathrm{~V})$ for power supply were placed in the baggage compartment of the aircraft, as no on-board power supply was available. The average power consumption of the HAIDI system in this configuration is $\sim 100 \mathrm{~W}$ at $12 \mathrm{~V}$ operating voltage, so the batteries could power the system for about two hours.

\subsection{Setup for Beechcraft model 76 Duchess}

HAIDI was also installed on the Airborne Laboratory for Atmospheric Research (ALAR) during two campaigns in Indiana and Alaska (USA) (Sects. 6.2 and 6.3). ALAR is a twinengined aircraft (Beechcraft Model 76 Duchess) operated by Purdue University and has a normal capacity of one pilot and three passengers. However, in ALAR the rear seats were removed in order to create sufficient space to install scientific instrumentation like HAIDI's instrument rack (Sect. 2.5). Also in this case, an external housing for the entrance optics was constructed. It is based on a Bopla diecast aluminum box (A $127 \mathrm{SIL}$ ) with the dimensions of $18 \times 18 \times 10 \mathrm{~cm}$. The box was mounted below the aircraft, on the left hand side of the lower shell (Fig. 17b), close to the location of the instrument rack. Directly above the box was a small aperture in the fuselage of the aircraft to guide the fiber optics and electric cables into the plane. For general protection and to reduce the aerodynamic drag, the box was surrounded by a fairing. The aluminum box contains the forward-looking telescope with shutter, a nadir scanner, a webcam for each viewing direction (resolution of $640 \times 480$ pixel), PE-foam for thermal insulation and a heating (Fig. 17). The heating (Cirrus 40/1 60 W) automatically turns on by a regulator if the temperature inside the box falls below a given value (usually $+10^{\circ} \mathrm{C}$ ), to avoid freezing of the windows. Each detector inside of HAIDI's instrument rack is connected to a netbook via USB. The netbooks store the recorded spectra, save the images from the two webcams, control the temperature of the CCDs and also log the spectrograph temperatures.

\subsection{Setup for High Altitude and Long Range Research Aircraft (HALO)}

In the near future, HAIDI will also be installed on the German research aircraft HALO. HALO is a modified Gulfstream G550 ultra-long range business jet, which is equipped with a wide range of instruments for atmospheric research. Beside HAIDI there are also some other optical remote sensing instruments to cover different scientific objectives, e.g., the HALO mini-DOAS (Hüneke et al., 2011) or APEX (Popp et al., 2012). As typical flight altitudes of HALO $(\sim 10 \mathrm{~km})$ are too high for the investigation of tropospheric trace gases with a limb system, HAIDI's forward-looking telescope will not be used in this case. Instead, three whiskbroom scanners will be applied in different directions: one in nadir direction and the other two tilted by $45^{\circ}$ into and against the flight direction. This setup allows to retrieve vertical profiles of trace gas plumes and aerosols without the need of a forward viewing direction. As a result, HAIDI's whole entrance optics can be installed inside the pressurized part of the aircraft on a socalled instrument plate, which is a standardized HALO instrument support structure. The plate is located on the lower shell of the aircraft and features a single quartz window in its center as viewing aperture for the telescopes. Calculations have shown that the window diameter and therefore its necessary thickness becomes minimal when arranging the three scanners as illustrated in Fig. 18a.

\section{Sample measurement results}

In the following, we present a series of sample applications of the HAIDI system, mostly intended to demonstrate its 
a)

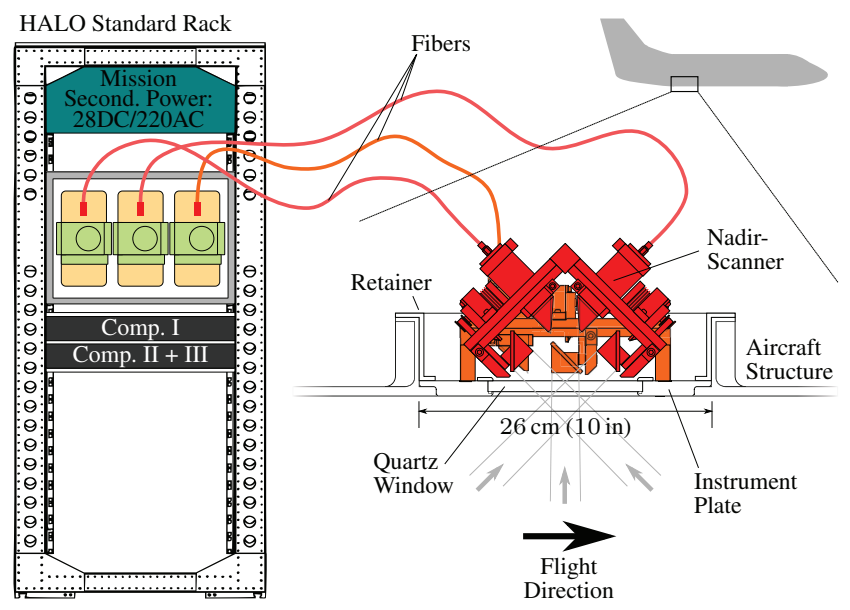

b)

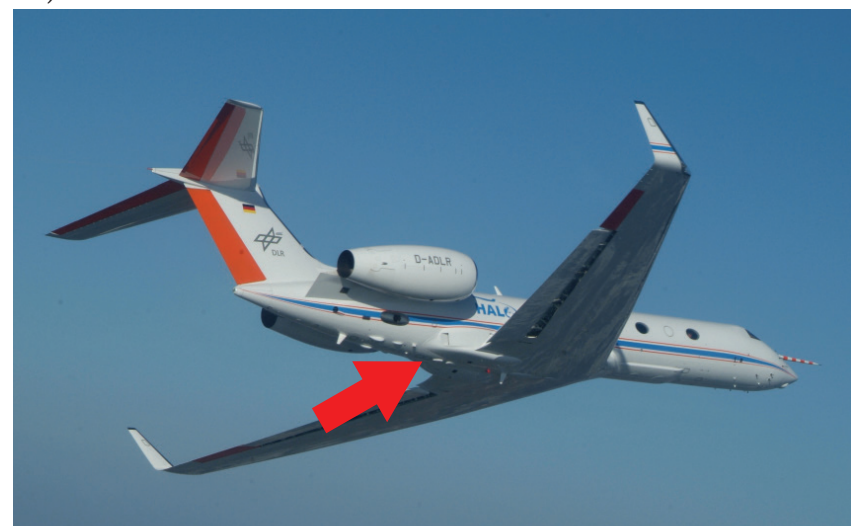

Figure 18. Planed instrumental setup for operation on the German research aircraft HALO: (a) Schematic showing the three whiskbroom scanners installed on a HALO instrument plate. The whiskbroom scanners are pointed to different directions in order to enable the recording of vertical profiles; one in nadir direction and the other two tilted by $\pm 45^{\circ}$ in flight direction. HAIDI's instrument rack and additional computers for data acquisition will be installed in a HALO standard rack. (b) Picture of HALO in flight (DLR, 2013), showing the preferred location for HAIDI in the rear (red arrow).

usefulness in a wide variety of studies on chemical and dynamical processes in the atmosphere.

\subsection{Mapping of volcanic emission plumes}

The first measurement campaign (campaign I in Table 1) with the HAIDI system was conducted in July 2011 on Sicily, Italy. For these flights, the system was installed on a Flight Design CTLS ultralight aircraft with the setup described in Sect. 5.1. In total, four flights to Mt. Etna and Mt. Stromboli were performed from a small airport $\left(37.800^{\circ}\right.$ $\left.\mathrm{N}, 15.228^{\circ} \mathrm{E}\right)$ close to Calatabiano in the northeast of Mt. Etna. The flight presented here took place between 08:00 and 10:30 UTC (10:00-12:30 LT) on 9 July. This day was

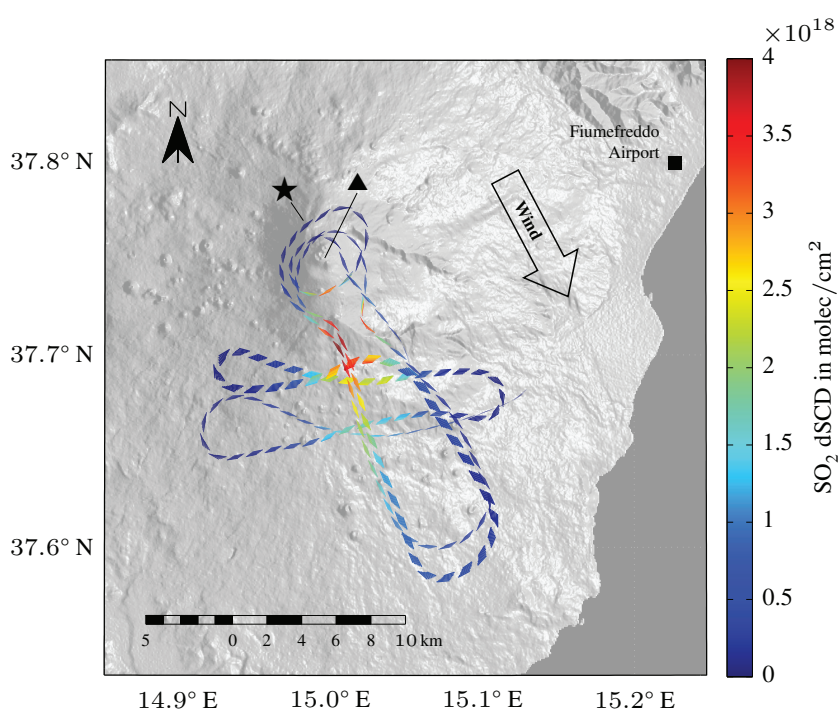

(a) $\mathrm{SO} 2$ distribution

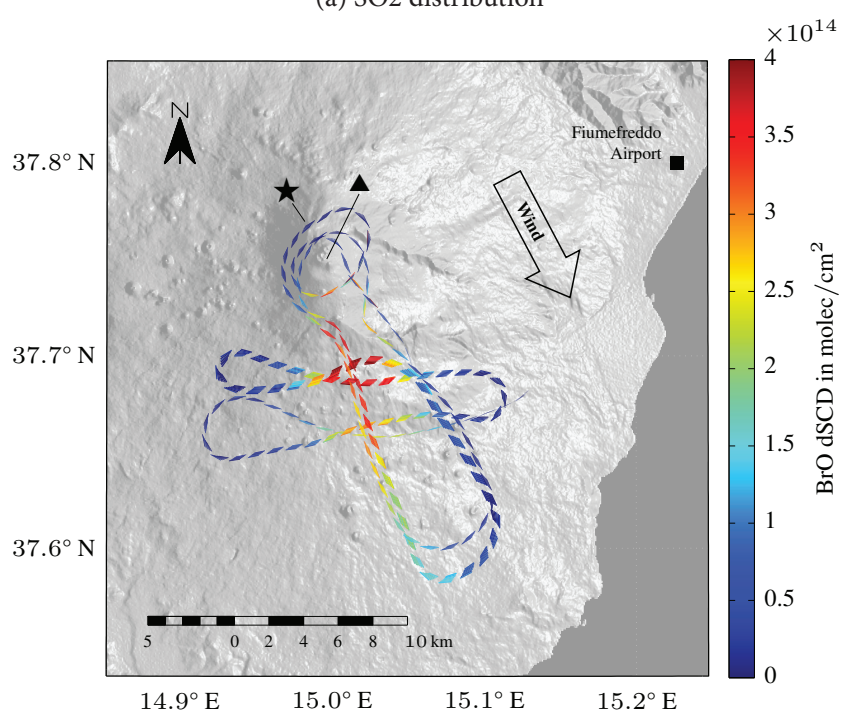

(b) $\mathrm{BrO}$ distribution

Figure 19. Maps showing the spatial distribution of $\mathrm{SO}_{2}$ and $\mathrm{BrO}$ measured by HAIDI's nadir scanner on 9 July 2011. Only data taken at altitudes greater than $3300 \mathrm{~m}$ is displayed here. The wind direction was taken from sounding balloon data (UWYO, 2011). $\star$ : Position of in-flight reference spectrum, $\boldsymbol{\Delta}$ : Location of Mt. Etna's New Southeast Crater.

particularly interesting because of the high volcanic activity. Only a few hours after the measurements a paroxysm occurred at Mt. Etna's New Southeast Crater (NSEC), which led to a temporal closure of the nearby Catania airport.

The measurements on Sicily mainly focused on the spatially high-resolved imaging of trace gases like $\mathrm{BrO}$ and $\mathrm{SO}_{2}$ in the volcanic emissions with the nadir scanner of the system. Topographic maps showing the spatial distribution of the above-mentioned trace gases are illustrated in Fig. 19. Because of the reasons discussed in Sect. 3.2, only 
measurements taken above the expected height of the plume, which is in good approximation at the height of the summit $(3300 \mathrm{~m})$, are displayed in these maps. Thus, the FOV of the nadir scanner is not projected to the ground in this case but rather to a horizontal plane at the expected height of the plume. Each plotted pixel thereby consists of 32 scans $(2 \times 16)$. As can be seen from Fig. 19, the flight track crosses several times the emission plume, where $\mathrm{SO}_{2} \mathrm{dSCDs}$ of up to $4.6 \times 10^{18}$ molec $\mathrm{cm}^{-2}$ could be observed along with $\mathrm{BrO}$ dSCDs of $4.1 \times 10^{14} \mathrm{molec}^{-2}$. A more detailed discussion of the measurement results, regarding the chemical evolution of the plume in terms of plume age, measurement location and time, can be found in General et al. (2014).

\subsection{Mapping of air pollution in urban regions}

The next measurement presented here is from a campaign in Indiana, USA, which took place in fall 2011 (campaign II in Table 1). During this campaign HAIDI was installed on a twin-engined Beechcraft Duchess from Purdue University (see Sect. 5.2) and performed three measurement flights to the metropolitan area of Indianapolis. The scientific objectives focused on the observation of air pollution over larger urban areas. In particular, the distribution of tropospheric $\mathrm{NO}_{2}$ was investigated, which can cause enhanced ground level ozone, the so-called photosmog, during sunny days and also contributes to acid rain, resulting from its oxidation to $\mathrm{HNO}_{3}$. Tropospheric $\mathrm{NO}_{2}$ mainly originates from anthropogenic sources such as the burning of fossil fuels, where it is primarily emitted as NO. The NO then rapidly reacts with $\mathrm{O}_{3}$, forming $\mathrm{NO}_{2}$. At the same time $\mathrm{NO}_{2}$ is photolyzed back to NO. Thus, the concentrations of $\mathrm{NO}$ and $\mathrm{NO}_{2}$ are usually in a photostationary state (Leighton, 1961). However, in heavily polluted areas high levels of peroxy radicals can lead to a deviation from the photostationary state.

The flights in Indiana were conducted from Purdue university airport $\left(40.412^{\circ} \mathrm{N}, 86.937^{\circ} \mathrm{W}\right)$, which is located in West Lafayette, Indiana (USA), about mid-way between the metropolitan areas of Indianapolis and Chicago. In the following, particularly the flight on 24 October should be addressed in more detail. Like all other flights of the campaign, it went to the urban area of Indianapolis, where several traverses were flown downwind of the city in order to investigate its emissions. The flight started at 16:31 UTC (12:31 LT) and lasted for about 2.5 hours. Figure 20 shows a part of the measured data plotted into a map of the area around Indianapolis. As can be seen, $\mathrm{NO}_{2}$ dSCDs of up to $2.4 \times 10^{16}$ molec $\mathrm{cm}^{-2}$ could be observed by HAIDI's nadir scanner. The spatial distribution furthermore reveals that the highest $\mathrm{NO}_{2}$ dSCDs were found southeast of the city core, following the wind direction from $310^{\circ}$ at $8 \mathrm{~m} \mathrm{~s}^{-1}$. A part of these $\mathrm{NO}_{2}$ emissions is caused by the coal-burning power plants of Indianapolis. The two largest of them, Harding Street Generating Station (nameplate capacity: 1170 MW) and Perry K Plant (nameplate capacity: 20 MW) are located

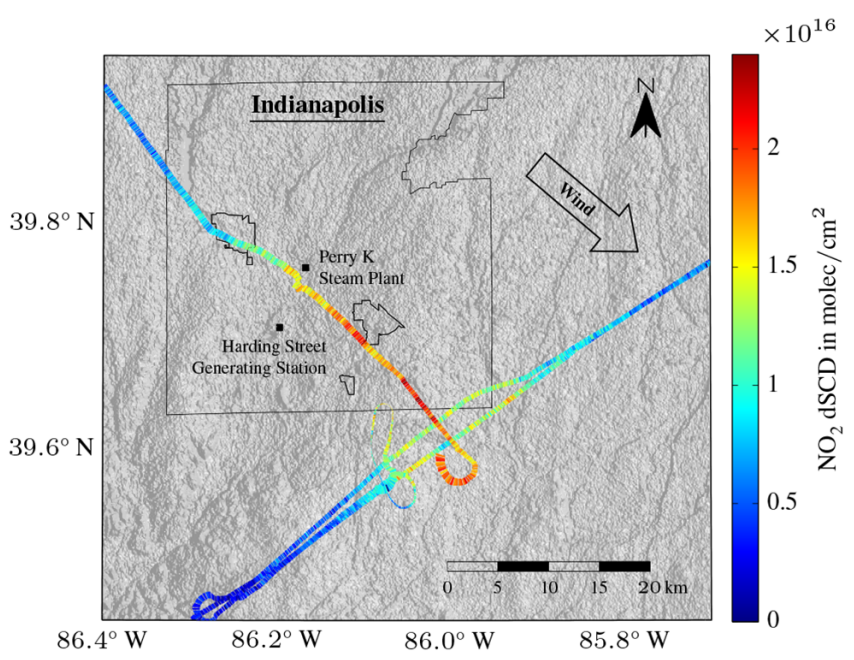

Figure 20. Detail of the flight on 24 October 2011 showing measured $\mathrm{NO}_{2}$ column densities plotted into a relief map of the area around Indianapolis (Indiana, USA). The displayed data was taken between 17:07 and 18:31 UTC with a binning of $1 \times 128$. Clearly visible is the $\mathrm{NO}_{2}$ plume originating from Indianapolis with its coal-burning power plants blowing downwind. For a better overview only data for flight altitudes below $1000 \mathrm{~m}$ are plotted here.

close to the center of the city (see Fig. 20). While the transect to the southeast follows the power plant plume, one can see the more diffuse mobile source $\mathrm{NO}_{2}$ emission in the transects that go perpendicular to the wind direction.

In addition to the visualization of the spatial distribution, measurement data from traverses flown downwind of the city can also be used to determine the approximate $\mathrm{NO}_{2}$ emission of Indianapolis (Ibrahim et al., 2010). For this purpose, the measured dSCDs were converted to tropospheric VCDs using a simple geometrical approximation for the air mass factor (Eq. 16). Assuming a stratospheric $\mathrm{NO}_{2} \mathrm{VCD}$ of $2.0 \times 10^{15} \mathrm{molec}^{-2}$ (Wenig et al., 2004) and negligible $\mathrm{NO}_{2}$ transport towards Indianapolis, the total $\mathrm{NO}_{2}$ emission $F_{\mathrm{NO}_{2}}$ of the probed area can be calculated by the following equation (Ibrahim et al., 2010):

$F_{\mathrm{NO}_{2}}=\sum_{i} V_{\text {trop }, \mathrm{NO}_{2}}\left(s_{i}\right) \cdot W \cdot \sin (\beta)\left(s_{i}\right) \cdot \boldsymbol{n} \cdot \Delta s_{i}$,

where $V_{\text {trop, } \mathrm{NO}_{2}}$ is the tropospheric VCD of $\mathrm{NO}_{2}, s_{i}$ the location of the $i$ th measurement, $W$ the average measured wind speed in the boundary layer, $\beta$ the angle between the wind direction and the heading angle of the aircraft, $n$ the normal vector parallel to Earth's surface and orthogonal to the current heading angle, and $\Delta s_{i}$ the distance traveled during the $i$ th measurement. The average wind speed $\left((7.7 \pm 1.9) \mathrm{m} \mathrm{s}^{-1}\right)$ and direction $\left((309 \pm 15)^{\circ}\right)$ were determined with an air flow measurement probe (best air turbulence probe) installed on the aircraft. Plugging in these values in Eq. (18) then yields a total $\mathrm{NO}_{2}$ emission of $(3.95 \pm 0.62) \mathrm{th}^{-1}$. 


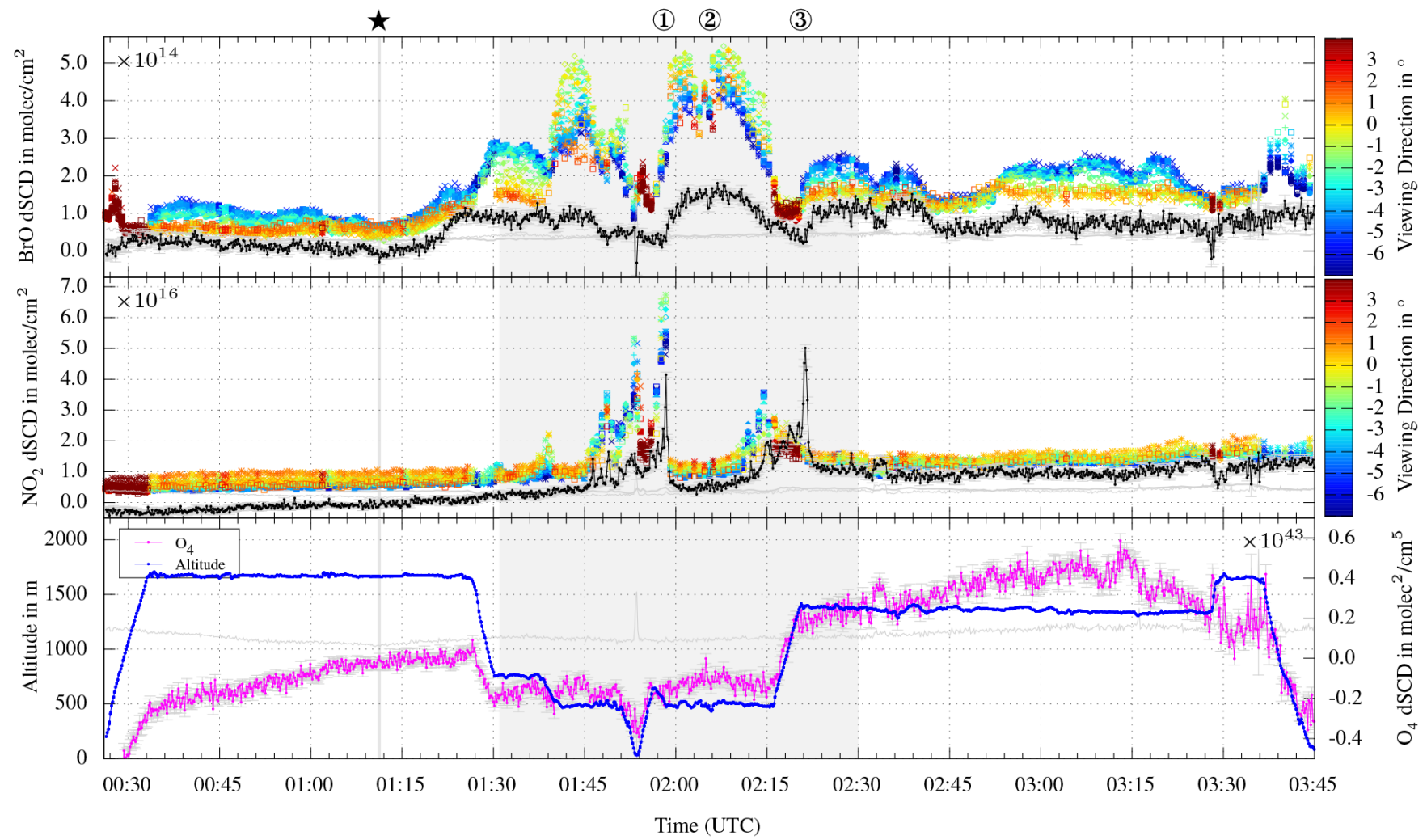

Figure 21. Time series of measurement data from the flight on 31 March 2012 between 00:25 and 03:45 UTC. Shaded in gray is the section of the flight around Prudhoe Bay, Alaska, which is also shown in Fig. 22. Forward (color-coded points) and nadir (solid black lines) measurements show enhanced $\mathrm{BrO}$ over the sea ice, around Northstar Island (2) and an anti-correlation with the observed $\mathrm{NO}_{2}$ values (1), (3). Errors and detection limits are plotted in gray. $\star$ : Time of in-flight reference spectrum for nadir scanner.

\subsection{Study of reactive bromine release processes in the Arctic}

In March 2012 the HAIDI system was again installed on the Beechcraft Duchess from Purdue University (campaign III in Table 1). This time, the flights were conducted from an airport in Barrow, Alaska, USA ( $\left.71.291^{\circ} \mathrm{N}, 156.789^{\circ} \mathrm{W}\right)$, in the framework of the BRomine, Ozone, and Mercury EXperiment (BROMEX) campaign (NASA, 2012). The instrumental setup for the campaign was very similar to the one used in Indiana and contains only some minor improvements. To account for the bright light conditions, the webcams for nadir and forward direction were equipped with additional UV and neutral density filters. During the BROMEX campaign a total of 11 measurement flights were done from which the one on 31 March 2012 is presented here.

Scientific objectives of the BROMEX campaign concentrate on the understanding of the chemical processes which release bromine to the polar atmosphere during springtime. These processes are responsible for an almost complete destruction of lower tropospheric ozone in polar regions and for the deposition of atmospheric mercury. Also the impact of Arctic sea ice reduction on these mechanisms was a subject of investigation. The HAIDI system contributed to BROMEX with airborne measurements of $\mathrm{BrO}$ and $\mathrm{NO}_{2}$.

The presented flight from 31 March was conducted at Prudhoe Bay, far to the east of Barrow. Prudhoe Bay is adjacent to the largest oil field in North America and also hosts one of the world's largest industrial complexes with an approximate annual $\mathrm{NO}_{\mathrm{x}}$ emission of $(12 \pm 4) \times 10^{3} \mathrm{t}$ (Jaffe et al., 1995). $\mathrm{NO}_{2}$, which is produced by the combustion of fossil fuels, acts as a sink for $\mathrm{BrO}$ by forming $\mathrm{BrONO}_{2}$. Thus, interesting anti-correlations between the distribution of $\mathrm{BrO}$ and $\mathrm{NO}_{2}$ could be observed on that day. Due to the large expansion of the flight track in the eastwest direction, the maps in Fig. 22 show only a detail of the flight within the area around Prudhoe Bay. A comparison of measurement data from nadir and forward viewing directions has shown that the tropospheric columns of $\mathrm{NO}_{2}$ and $\mathrm{BrO}$ in the used reference spectra can be neglected. Therefore, Eq. (16) was used to convert the displayed data in the maps to tropospheric VCDs by assuming stratospheric $\mathrm{BrO}$ and $\mathrm{NO}_{2}$ VCDs of $5 \times 10^{13}$ molec $\mathrm{cm}^{-2}$ (Choi, 2010) and $2.5 \times 10^{15}$ molec $\mathrm{cm}^{-2}$ (Wenig et al., 2004), respectively. As can be seen in the maps, the highest $\mathrm{BrO}$ column densities were seen offshore on that day. The nadir scanner 

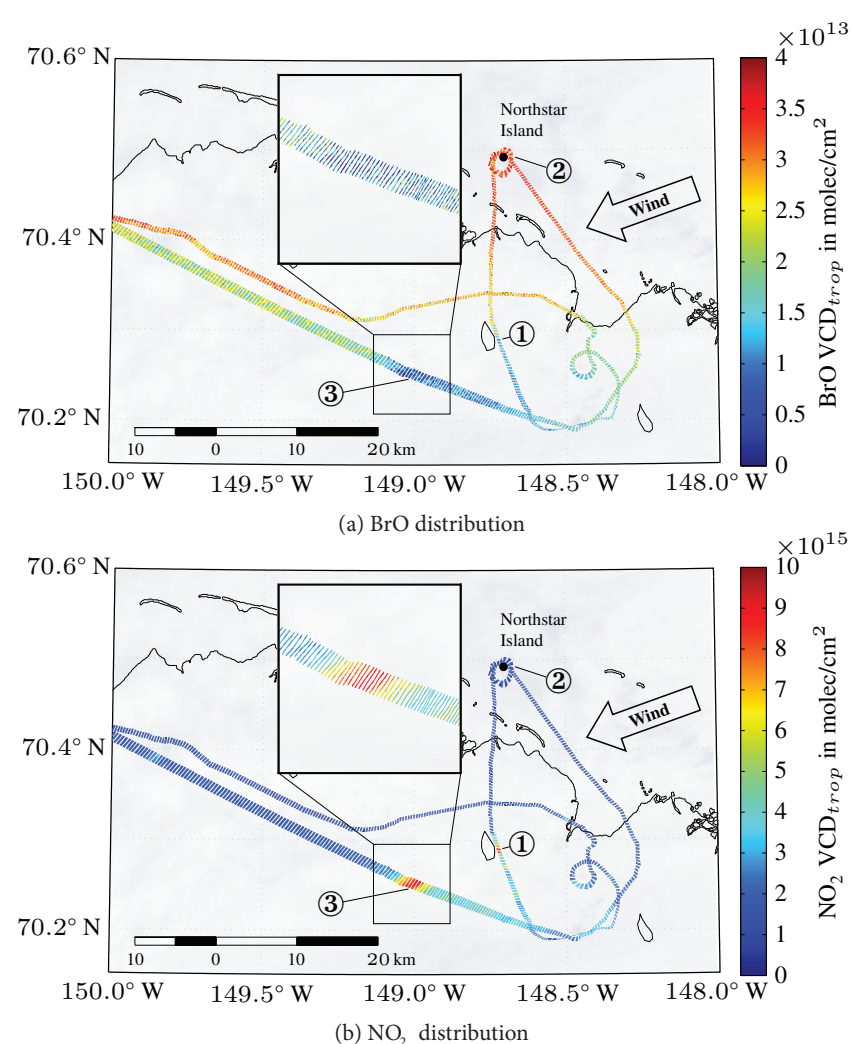

Figure 22. Maps showing a part of the data from the flight to Prudhoe Bay on 31 March 2012 (01:31-02:30 UTC, gray shaded section in Fig. 21), measured by HAIDI's nadir scanner. Noticeable in the observed trace gas distribution is an anti-correlation between $\mathrm{BrO}$ and $\mathrm{NO}_{2}$ column densities (1), (2), (3)). The background shows a true color satellite image taken from MODIS (Aqua) on the same day with a resolution of $250 \mathrm{~m}$ (NASA, 2012).

measured $\mathrm{BrO}$ dSCDs of up to $1.7 \times 10^{14} \mathrm{molec}^{-2}$ $\left(\mathrm{VCD}_{\text {trop }} \approx 3.7 \times 10^{13} \mathrm{molec}^{-2}\right)$ and also the forwardlooking telescope shows clearly increasing column densities in the same area. At the location of enhanced $\mathrm{BrO}$, the observed $\mathrm{NO}_{2}$ column densities were always close to zero. The opposite effect was found further to the south (1), (3), where high $\mathrm{NO}_{2} \mathrm{dSCDs}$ of about $5.0 \times 10^{16} \mathrm{molec} \mathrm{cm}^{-2}$ ( $\mathrm{VCD}_{\text {trop }} \approx 8.2 \times 10^{15} \mathrm{molec}^{-2}$ ) could be seen by the nadir scanner together with a local $\mathrm{BrO}$ minimum. This location is also shown with a higher spatial resolution (binning: $1 \times 8 \Rightarrow$ resolution: $39 \times 137 \mathrm{~m}$ ) in the magnification view of Fig. 22b. Here, one can clearly see that the $\mathrm{NO}_{2}$ plume, originating from the industrial complexes of Prudhoe Bay, propagates with the wind along the ENE-WSW direction.

The $\mathrm{NO}_{2}$-enriched air masses at Prudhoe Bay were also seen by GOME-2 (MetOp), which passed over the area only a few hours before HAIDI. Despite this temporal offset measurements from GOME-2 and HAIDI show a very good agreement in the spatial distribution of $\mathrm{NO}_{2}$ (see Fig. 23).
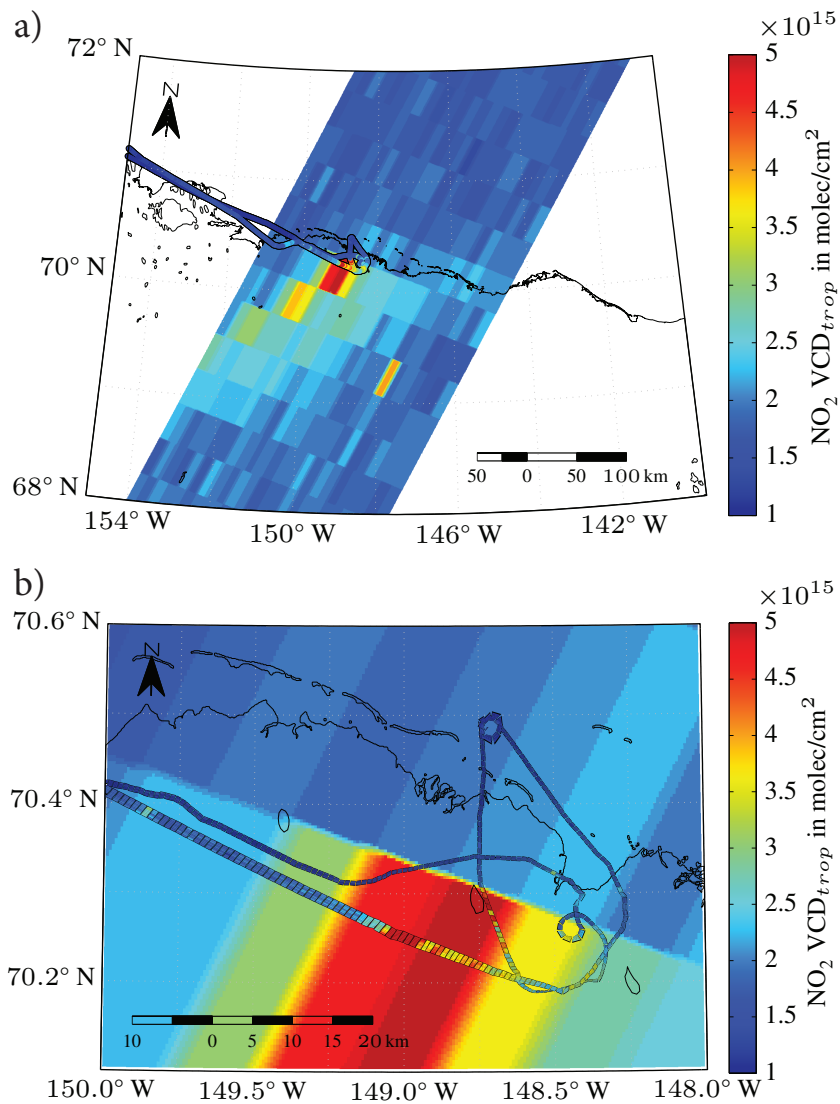

Figure 23. Comparison of $\mathrm{NO}_{2}$ VCDs around Prudhoe Bay, measured by GOME-2 (DLR, 2012) and HAIDI: (a) The GOME-2 satellite swath covered Prudhoe Bay on 30 March at 21:02 UTC, $4.5 \mathrm{~h}$ prior to the measurements with HAIDI. As can be seen, the satellite data shows a large $\mathrm{NO}_{2}$ plume propagating in wind direction. Measurements from HAIDI are indicated by color-coded dots. (b) The enlarged view shows that enhanced $\mathrm{NO}_{2}$ was only seen onshore. Due to favorable pixel positions in the satellite swath this can also be confirmed by the GOME- 2 measurements, which have a much lower resolution.

\section{Conclusions}

The newly developed Heidelberg Airborne Imaging DOAS Instrument (HAIDI) has proved to be a powerful tool for atmospheric measurements. Its specially designed spectrographs cover a broad spectral region, ranging from 300 to $450 \mathrm{~nm}$ (instantaneous coverage for a fixed grating position: $107 \mathrm{~nm}$ ), with a resolution of about $0.5 \mathrm{~nm}$. This allows to detect a large number of important trace gases like $\mathrm{NO}_{2}, \mathrm{SO}_{2}$, $\mathrm{BrO}, \mathrm{OClO}$ and $\mathrm{O}_{4}$ at the same time. Thanks to the possibility of operating HAIDI with different kinds of entrance optics (pushbroom and whiskbroom scanner), the system can be installed on a variety of aircraft. Both entrance optics as well as spectrometer and detector are optimized in terms of light throughput and spatial resolution. Thus, by combining multiple viewing directions (e.g., three whiskbroom scanners 
or one whiskbroom and one pushbroom scanner) the system can map the spatial distribution of the above-mentioned trace gases in two and three dimensions on a large scale and with high resolution. For example, when flying at an altitude of $10000 \mathrm{~m}$, the nadir whiskbroom scanner will cover an area of almost $10 \mathrm{~km}$ width with a resolution of up to $300 \mathrm{~m}$.

In a total of 18 measurement flights up to now, realized with two different aircraft, the HAIDI system could yield first valuable measurement results. During a campaign in July 2011, the volcanic emission plume of Mount Etna (Sicily, Italy) was mapped, showing $\mathrm{BrO} / \mathrm{SO}_{2}$ ratios of about $1.5 \times 10^{-4}$. This value is in good agreement with prior measurements by e.g., Vogel (2011) or Bobrowski et al. (2007). Further flights were conducted in the metropolitan area of Indianapolis (Indiana, USA) in fall of the same year. Here the trace gas mapping could reveal $\mathrm{NO}_{2}$-enriched air masses originating from the city. In addition the approximate $\mathrm{NO}_{2}$ emission of Indianapolis could be determined to $(3.95 \pm 0.62) \mathrm{th}^{-1}$ on the basis of these measurements. Moreover, the HAIDI system participated in the BROMEX campaign in March 2012. During several flights large-scale $\mathrm{BrO}$ distributions could successfully be observed around Barrow, Alaska. Also clear anti-correlations in the spatial distribution of $\mathrm{BrO}$ and $\mathrm{NO}_{2}$ were seen. These measurements can make a significant contribution to improve the general knowledge about polar ozone depletion events (ODEs).

Future measurements on the research aircraft HALO are planed to be accomplished in 2015. The considerably higher flight altitude and faster cruise speed of HALO in comparison to the here presented flights will allow the HAIDI system to cover much larger areas. This will especially be important to validate and complement global satellite measurements.

Acknowledgements. The development of HAIDI was funded by the Deutsche Forschungsgemeinschaft (DFG) within the Priority Program (SPP) No. 1294 "HALO" (DFG PF-384 7/1 and 7/2), which is gratefully acknowledged. We acknowledge financial support by Deutsche Forschungsgemeinschaft and RuprechtKarls-Universität Heidelberg within the funding programme Open Access Publishing. Furthermore, we are very thankful to the following people for general support and for making the presented measurement campaigns possible:

- Etna Campaign: We thank Uwe Post for the permission to install HAIDI on the CTLS ultralight and also for piloting the aircraft. Joelle Buxmann, Moritz Jurgschat, Lara Penth and Andreas Vogel for assisting with the instrument installation. Moreover we want to thank the operators of Fiumefreddo airfield for helping out with tools, etc.

- Indianapolis Campaign: We thank all members of Shepson Atmospheric Chemistry Group, especially Dana Caulton for providing the ALAR INS data. Furthermore we want to thank the team from Purdue university airport.

-Barrow Campaign: We thank NASA for funding the BRomine, Ozone, and Mercury EXperiment (BROMEX) campaign and for the opportunity to participate, especially Son V. Nghiem as the Principal Investigator. We thank Dana Caulton, Kerri Pratt and the rest of the Shepson Atmospheric Chemistry Group. We also thank Peter Peterson and Steve Walsh from the University of Alaska Fairbanks for scientific support. In addition we want to thank all other members of the BROMEX campaign for the excellent cooperation.

Edited by: M. Van Roozendael

\section{References}

Baidar, S., Oetjen, H., Coburn, S., Dix, B., Ortega, I., Sinreich, R., and Volkamer, R.: The CU Airborne MAX-DOAS instrument: vertical profiling of aerosol extinction and trace gases, Atmos. Meas. Tech., 6, 719-739, doi:10.5194/amt-6-719-2013, 2013.

Beirle, S., Platt, U., von Glasow, R., Wenig, M., and Wagner, T.: Estimate of nitrogen oxide emissions from shipping by satellite remote sensing, Geophys. Res. Lett., 31, L18102, doi:10.1029/2004GL020312, 2004.

Beirle, S., Boersma, K. F., Platt, U., Lawrence, M., and Wagner, T.: Megacity Emissions and Lifetimes of Nitrogen Oxides Probed from Space, Science, 333, 1737-1739, 2011.

Berg, N., Mellqvist, J., Jalkanen, J.-P., and Balzani, J.: Ship emissions of $\mathrm{SO}_{2}$ and $\mathrm{NO}_{2}$ : DOAS measurements from airborne platforms, Atmos. Meas. Tech., 5, 1085-1098, doi:10.5194/amt-51085-2012, 2012.

Bobrowski, N., von Glasow, R., Aiuppa, A., Inguaggiato, S., Louban, I., Ibrahim, O. W., and Platt, U.: Reactive halogen chemistry in volcanic plumes, J. Geophys. Res., 112, D06311, doi:10.1029/2006JD007206, 2007.

Bobrowski, N., Kern, C., Platt, U., Hörmann, C., and Wagner, T.: Novel $\mathrm{SO}_{2}$ spectral evaluation scheme using the 360$390 \mathrm{~nm}$ wavelength range, Atmos. Meas. Tech., 3, 879-891, doi:10.5194/amt-3-879-2010, 2010.

Bruns, M., Buehler, S. A., Burrows, J. P., Heue, K.-P., Platt, U., Pundt, I., Richter, A., Rozanov, A., Wagner, T., and Wang, P.: Retrieval of profile information from airborne multiaxis UV-visible skylight absorption measurements, Appl. Opt., 43, 4415-4426, doi:10.1364/AO.43.004415, 2004.

Bruns, M., Buehler, S. A., Burrows, J. P., Richter, A., Rozanov, A., Wang, P., Heue, K. P., Platt, U., Pundt, I., and Wagner, T.: $\mathrm{NO}_{2}$ Profile retrieval using airborne multi axis UV-visible skylight absorption measurements over central Europe, Atmos. Chem. Phys., 6, 3049-3058, doi:10.5194/acp-6-3049-2006, 2006.

Choi, S.: Estimating Stratospheric and Tropospheric BrO columns using Ozone Monitoring Instrument, in: NASA Goddard/Graduate Student Summer Program in Earth System Science, 2010.

Clémer, K., Roozendael, M. V., Fayt, C., Hendrick, F., Hermans, C., Pinardi, G., Spurr, R., Wang, P., and Mazière, M. D.: Multiple wavelength retrieval of tropospheric aerosol optical properties from MAXDOAS measurements in Beijing, Atmos. Meas. Tech., 3, 863-878, doi:10.5194/amt-3-863-2010, 2010.

Deutschmann, T., Beirle, S., Frieß, U., Grzegorski, M., Kern, C., Kritten, L., Platt, U., Prados-Roman, C., Puķite, J., Wagner, T., Werner, B., and Pfeilsticker, K.: The Monte Carlo atmospheric radiative transfer model McArtim: Introduction and validation of Jacobians and 3D features, J. Quant. Spec. Rad. Trans., 112, 1119-1137, doi:10.1016/j.jqsrt.2010.12.009, 2011. 
Dix, B., Brenninkmeijer, C. A. M., Frieß, U., Wagner, T., and Platt, U.: Airborne multi-axis DOAS measurements of atmospheric trace gases on CARIBIC long-distance flights, Atmos. Meas. Tech., 2, 639-652, doi:10.5194/amt-2-639-2009, 2009.

Dix, B., Baidar, S., Bresch, J. F., Hall, S. R., Schmidt, K. S., Wang, S., and Volkamer, R.: Detection of iodine monoxide in the tropical free troposphere, Proc. Natl. Acad. Sci. USA, 110, 20352040, doi:10.1073/pnas.1212386110, 2013.

DLR: available at: http://atmos.eoc.dlr.de/gome2/ (last access: 29 September 2014), 2012.

DLR: available at: http://www.dlr.de/dlr/desktopdefault.aspx/ tabid-10630/ (last access: 29 September 2014), 2013.

Fellers, T. J. and Davidson, M. W.: Concepts in Digital Imaging Technology - CCD Saturation and Blooming, http://hamamatsu. magnet.fsu.edu/articles/ccdsatandblooming.html (last access: 29 September 2014), 2014.

Fleischmann, O., Hartmann, M., Burrows, J., and Orphal, J.: New ultraviolet absorption cross-sections of $\mathrm{BrO}$ at atmospheric temperatures measured by a timewindowing Fourier transform spectroscopy, J. Photochem. Photobiol. A.: Chem., 168, 117-132, 2004.

Frieß, U., Monks, P., Remedios, J., Rozanov, A., Sinreich, R., Wagner, T., and Platt, U.: MAX-DOAS $\mathrm{O}_{4}$ measurements: A new technique to derive information on atmospheric aerosols: 2. Modeling studies, J. Geophys. Res., 111, D14203, doi:10.1029/2005JD006618, 2006.

Frieß, U., Sihler, H., Sander, R., Pöhler, D., Yilmaz, S., and Platt, U.: The vertical distribution of $\mathrm{BrO}$ and aerosols in the Arctic: Measurements by active and passive differential optical absorption spectroscopy, J. Geophys. Res., 116, D00R04, doi:10.1029/2011JD015938, 2011.

General, S.: Development of the Heidelberg Airborne Imaging DOAS Instrument (HAIDI), Ph.D. thesis, University of Heidelberg, 2014.

General, S., Bobrowski, N., Pöhler, D., Weber, K., Fischer, C., and Platt, U.: Airborne I-DOAS measurements at Mt. Etna $\mathrm{BrO}$ and $\mathrm{OClO}$ evolution in the plume, J. Volcanol. Geoth. Res., doi:10.1016/j.jvolgeores.2014.05.012, 2014.

Grainger, J. and Ring, J.: Anomalous Fraunhofer Line Profiles, Nature, 193, 762, doi:10.1038/193762a0, 1962.

Hartl, A., Song, B. C., and Pundt, I.: 2-D reconstruction of atmospheric concentration peaks from horizontal long path DOAS tomographic measurements: parametrisation and geometry within a discrete approach, Atmos. Chem. Phys., 6, 847-861, doi:10.5194/acp-6-847-2006, 2006.

Hermans, C., Vandaele, A., Carleer, M., Fally, S., Colin, R., Jenouvrier, A., Coquart, B., and Mérienne, M.: Absorption crosssections of atmospheric constituents: $\mathrm{NO}_{2}, \mathrm{O}_{2}$, and $\mathrm{H}_{2} \mathrm{O}$, Environ. Sci. Pollut. R., 6, 151-158, 1999.

Heue, K.-P.: Airborne Multi AXis DOAS instrument and measurements of two-dimensional tropospheric trace gas distributions, Ph.D. thesis, University of Heidelberg, 2005.

Heue, K.-P., Richter, A., Bruns, M., Burrows, J. P., v. Friedeburg, C., Platt, U., Pundt, I., Wang, P., and Wagner, T.: Validation of SCIAMACHY tropospheric $\mathrm{NO}_{2}$-columns with AMAXDOAS measurements, Atmos. Chem. Phys., 5, 1039-1051, doi:10.5194/acp5-1039-2005, 2005.

Heue, K.-P., Wagner, T., Broccardo, S. P., Walter, D., Piketh, S. J., Ross, K. E., Beirle, S., and Platt, U.: Direct observation of two dimensional trace gas distributions with an airborne Imaging DOAS instrument, Atmos. Chem. Phys., 8, 6707-6717, doi:10.5194/acp-8-6707-2008, 2008.

Heue, K.-P., Brenninkmeijer, C. A. M., Baker, A. K., RautheSchöch, A., Walter, D., Wagner, T., Hörmann, C., Sihler, H., Dix, B., Frieß, U., Platt, U., Martinsson, B. G., van Velthoven, P. F. J., Zahn, A., and Ebinghaus, R.: $\mathrm{SO}_{2}$ and $\mathrm{BrO}$ observation in the plume of the Eyjafjallajökull volcano 2010: CARIBIC and GOME-2 retrievals, Atmos. Chem. Phys., 11, 2973-2989, doi:10.5194/acp-11-2973-2011, 2011.

Hüneke, T., Ludmann, S., and Pfeilsticker, K.: A novel UV/vis/near IR optical spectrometer for limb and nadir measurements of atmospheric radiation and trace gases, Geophys. Res. Abstr., EGU2011-7089, EGU General Assembly 2011, Vienna, Austria, 2011.

Ibrahim, O., Shaiganfar, R., Sinreich, R., Stein, T., Platt, U., and Wagner, T.: Car MAX-DOAS measurements around entire cities: quantification of $\mathrm{NO}_{\mathrm{X}}$ emissions from the cities of Mannheim and Ludwigshafen (Germany), Atmos. Meas. Tech., 3, 709-721, doi:10.5194/amt-3-709-2010, 2010.

Irie, H., Kanaya, Y., Akimoto, H., Iwabuchi, H., Shimizu, A., and Aoki, K.: First retrieval of tropospheric aerosol profiles using MAX-DOAS and comparison with lidar and sky radiometer measurements, Atmos. Chem. Phys., 8, 341-350, doi:10.5194/acp-8341-2008, 2008

Jaffe, D. A., Honrath, R. E., Furness, D., Conway, T. J., Dlugokencky, E., and Steele, L. P.: A determination of the $\mathrm{CH}_{4}, \mathrm{NO}_{x}$ and $\mathrm{CO}_{2}$ emissions from the Prudhoe Bay, Alaska oil development, J. Atmos. Chem., 20, 213-227, 1995.

Kern, C., Deutschmann, T., Vogel, L., Wöhrbach, M., Wagner, T., and Platt, U.: Radiative transfer corrections for accurate spectroscopic measurements of volcanic gas emissions, Bull. Volcanol., 72, 233-247, 2010.

Kidger, M. J.: Fundamental Optical Design, SPIE Press, 2002.

Kowalewski, M. G. and Janz, S. J.: Remote sensing capabilities of the Airborne Compact Atmospheric Mapper, in: Proc. SPIE, vol. 7452 of Earth Observing Systems XIV, p. 74520Q, 2009.

Kraus, S.: DOASIS - A Framework Design for DOAS, Ph.D. thesis, University of Mannheim, 2006.

Kromminga, H., Orphal, J., Voigt, S., and Burrows, J.: Fouriertransform-spectroscopy of symmetric chlorine dioxide (OClO), Proc. EC Advanced Study Course "Atmospheric Effects of aircraft emissions in the upper troposphere and lower stratosphere" (ASTAIRE 1999), Bergen, Norway, 1999.

Kurucz, R. L., Furenlid, I., Brault, J., and Testerman, L.: Solar flux atlas from 296 to $1300 \mathrm{~nm}$, National Solar Observatory, 1984.

Laepple, T., Knab, V., Mettendorf, K.-U., and Pundt, I.: Longpath DOAS tomography on a motorway exhaust gas plume: numerical studies and application to data from the BAB II campaign, Atmos. Chem. Phys., 4, 1323-1342, doi:10.5194/acp-4-1323-2004, 2004.

Leighton, P. A.: Photochemistry of air pollution, Academic Press, New York, 1961.

Liou, K. N.: An Introduction to Atmospheric Radiation, 2nd Edn., Academic Press, 2002.

Louban, I.: Zweidimensionale Spektroskopische Aufnahmen von Spurenstoff-Verteilungen, Master's thesis, University of Heidelberg, 2005 . 
McElroy, C. T., McLinden, C. A., and McConnell, J. C.: Evidence for bromine monoxide in the free troposphere during the Arctic polar sunrise, Nature, 397, 338-341, 1999.

Melamed, M. L., Solomon, S., Daniel, J. S., Langford, A. O., Portmann, R. W., Ryerson, T. B., Jr., D. K. N., and McKeen, S. A.: Measuring reactive nitrogen emissions from point sources using visible spectroscopy from aircraft, J. Environ. Monitor., 5, 2934, 2003.

Meller, R. and Moortgat, G.: Temperature dependence of the absorption cross sections of formaldehyde between 223 and $323 \mathrm{~K}$ in the wavelength range $225-375 \mathrm{~nm}$, J. Geophys. Res., 105, 7089-7101, 2000.

Merlaud, A., Van Roozendael, M., Theys, N., Fayt, C., Hermans, C., Quennehen, B., Schwarzenboeck, A., Ancellet, G., Pommier, M., Pelon, J., Burkhart, J., Stohl, A., and De Mazière, M.: Airborne DOAS measurements in Arctic: vertical distributions of aerosol extinction coefficient and $\mathrm{NO}_{2}$ concentration, Atmos. Chem. Phys., 11, 9219-9236, doi:10.5194/acp-11-9219-2011, 2011.

Merlaud, A., Roozendael, M. V., van Gent, J., Fayt, C., Maes, J., Toledo-Fuentes, X., Ronveaux, O., and Maziére, M. D.: DOAS measurements of $\mathrm{NO}_{2}$ from an ultralight aircraft during the Earth Challenge expedition, Atmos. Meas. Tech., 5, 2057-2068, doi:10.5194/amt-5-2057-2012, 2012.

NASA: available at: http://lance-modis.eosdis.nasa.gov/imagery/ subsets/?subset=BROMEX (last access: 29 September 2014), 2012.

Neumann, W.: available at: http://www.spectra-magic.de (last access: 8 April 2014), 2013.

Palmer, C. and Loewen, E.: Diffraction Grating Handbook, Newport Corporation, 2005.

Petritoli, A., Ravegnani, F., Giovanelli, G., Bortoli, D., Bonafè, U., Kostadinov, I., and Oulanovsky, A.: Off-axis measurements of atmospheric trace gases by use of an airborne ultraviolet-visible spectrometer, Appl. Opt., 41, 5593-5599, 2002.

Pfeilsticker, K. and Platt, U.: Airborne measurements during the Arctic stratospheric experiment: Observation of $\mathrm{O}_{3}$ and $\mathrm{NO}_{2}$, Geophys. Res. Lett., 21, 1375-1378, 1994.

Platt, U. and Stutz, J.: Differential Optical Absorption Spectroscopy, Springer-Verlag Berlin Heidelberg, 2008.

Pöhler, D.: Determination of two dimensional trace gas distributions using tomographic LP-DOAS measurements in the city of Heidelberg, Germany, Ph.D. thesis, University of Heidelberg, 2010.

Popp, C., Brunner, D., Damm, A., Roozendael, M. V., Fayt, C., and Buchmann, B.: High-resolution $\mathrm{NO}_{2}$ remote sensing from the Airborne Prism EXperiment (APEX) imaging spectrometer, Atmos. Meas. Tech., 5, 2211-2225, 2012, http://www.atmos-meas-tech.net/5/2211/2012/.

Prados-Roman, C., Butz, A., Deutschmann, T., Dorf, M., Kritten, L., Minikin, A., Platt, U., Schlager, H., Sihler, H., Theys, N., Roozendael, M. V., Wagner, T., and Pfeilsticker, K.: Airborne DOAS limb measurements of tropospheric trace gas profiles: case studies on the profile retrieval of $\mathrm{O}_{4}$ and $\mathrm{BrO}$, Atmos. Meas. Tech., 4, 1241-1260, doi:10.5194/amt-4-1241-2011, 2011.

Rodgers, C. D.: Inverse methods for atmospheric sounding, theory and practice, Series on Atmospheric, Oceanic and Planetary Physics, World Scientific, 2000.

Rozanov, A., Rozanov, V., and Burrows, J.: A numerical radiative transfer model for a spherical planetary atmosphere: combined differential-integral approach involving the Picard itera- tive approximation, J. Quant. Spec. Rad. Trans., 69, 491-512, doi:10.1016/S0022-4073(00)00100-X, 2001.

Schowengerdt, R. A.: Remote Sensing: Models and Methods for Image Processing, Academic Press, 2006.

Sinreich, R., Frieß, U., and Platt, U.: Multi axis differential optical absorption spectroscopy (MAX-DOAS) of gas and aerosol distributions, Faraday Discuss., 130, 153-164, doi:10.1039/b419274p, 2005.

Stutz, J.: Messung der Konzentration troposphärischer Spurenstoffe mittels Differentieller-Optischer-Absorptionsspektroskopie: Eine neue Generation von Geräten und Algorithmen, Ph.D. thesis, Institute of Environmental Physics, Heidelberg University, 1996.

Stutz, J. and Platt, U.: Numerical analysis and estimation of the statistical error of differential optical absorption spectroscopy measurements with least-squares methods, Appl. Opt., 35, 60416053, 1996.

UWYO: University of Wyoming - Department of Atmospheric Science, available at: http://weather.uwyo.edu/upperair/sounding. html (last access: 29 September 2014), 2011.

Vandaele, A., Hermans, C., and Fally, S.: Fourier transform measurements of $\mathrm{SO}_{2}$ absorption cross sections: II. Temperature dependence in the $29000-44000 \mathrm{~cm}^{-1}(227-345 \mathrm{~nm})$ region, J. Quant. Spectrosc. Radiat. Transfer, 110, 2115-2126, 2009.

Vogel, L.: Volcanic plumes: Evaluation of spectroscopic measurements, early detection, and bromine chemistry, Ph.D. thesis, University of Heidelberg, 2011.

Vogel, L., Galle, B., Kern, C., Delgado Granados, H., Conde, V., Norman, P., Arellano, S., Landgren, O., Lübcke, P., Alvarez Nieves, J. M., Cárdenas Gonzáles, L., and Platt, U.: Early inflight detection of $\mathrm{SO}_{2}$ via Differential Optical Absorption Spectroscopy: a feasible aviation safety measure to prevent potential encounters with volcanic plumes, Atmos. Meas. Tech., 4, 17851804, doi:10.5194/amt-4-1785-2011, 2011.

Voigt, S., Orphal, J., and Burrows, J.: The temperature dependence (203-293 K) of the absorption cross sections of $\mathrm{O}_{3}$ in the 230$850 \mathrm{~nm}$ region measured by Fourier-transform spectroscopy, J. Photochem. Photobiol. A: Chem., 143, 1-9, 2001.

Voigt, S., Orphal, J., and Burrows, J.: The temperature and pressure dependence of the absorption cross-sections of $\mathrm{NO}_{2}$ in the 250-800 nm region measured by Fouriertransform spectroscopy, J. Photochem. Photobiol. A: Chem., 143, 1-7, 2002.

Wagner, T., Dix, B., von Friedeburg, C., Frieß, U., Sanghavi, S., Sinreich, R., and Platt, U.: MAX-DOAS $\mathrm{O}_{4}$ measurements: A new technique to derive information on atmospheric aerosols - principles and information content, J. Geophys. Res., 109, D22205, doi:10.1029/2004JD004904, 2004.

Wagner, T., Beirle, S., and Deutschmann, T.: Three-dimensional simulation of the Ring effect in observations of scattered sun light using Monte Carlo radiative transfer models, Atmos. Meas. Tech., 2, 113-124, doi:10.5194/amt-2-113-2009, 2009.

Wagner, T., Beirle, S., Brauers, T., Deutschmann, T., Frieß, U., Hak, C., Halla, J. D., Heue, K. P., Junkermann, W., Li, X., Platt, U., and Pundt-Gruber, I.: Inversion of tropospheric profiles of aerosol extinction and $\mathrm{HCHO}$ and $\mathrm{NO}_{2}$ mixing ratios from MAX-DOAS observations in Milano during the summer of 2003 and comparison with independent data sets, Atmos. Meas. Tech., 4, 2685-2715, doi:10.5194/amt-4-2685-2011, 2011. 
Wahner, A., Callies, J., Dorn, H.-P., Platt, U., and Schiller, C.: Near UV Atmospheric Absorption Measurements of Column Abundances During Airborne Arctic Stratospheric Expedition, Jan.Feb. 1989: 1. Technique and $\mathrm{NO}_{2}$ Observations, Geophys. Res. Lett., 17, 497-500, 1990.

Wan, Z., Zhang, Y., Ma, X., King, M. D., Myers, J. S., and Li, X.: Vicarious calibration of the Moderate-Resolution Imaging Spectroradiometer Airborne Simulator thermal-infrared channels, Appl. Opt., 38, 6294-6306, 1999.

Wang, P., Richter, A., Bruns, M., Rozanov, V. V., Burrows, J. P., Heue, K.-P., Wagner, T., Pundt, I., and Platt, U.: Measurements of tropospheric $\mathrm{NO}_{2}$ with an airborne multi-axis DOAS instrument, Atmos. Chem. Phys., 5, 337-343, doi:10.5194/acp-5-337-2005, 2005.
Wang, P., Richter, A., Bruns, M., Burrows, J. P., Scheele, R., Junkermann, W., Heue, K.-P., Wagner, T., Platt, U., and Pundt, I.: Airborne multi-axis DOAS measurements of tropospheric $\mathrm{SO}_{2}$ plumes in the Po-valley, Italy, Atmos. Chem. Phys., 6, 329-338, doi:10.5194/acp-6-329-2006, 2006.

Wenig, M., Kühl, S., Beirle, S., Bucsela, E., Jähne, B., Platt, U., Gleason, J., and Wagner, T.: Retrieval and analysis of stratospheric $\mathrm{NO}_{2}$ from the Global Ozone Monitoring Experiment, J. Geophys. Res., 109, D04315, doi:10.1029/2003JD003652, 2004.

Williams, M. D.: Laser reflection from oxide-coated aluminum, Appl. Opt., 21, 747-750, doi:10.1364/AO.21.000747, 1982. 